\title{
TECHNOLOGY PRACTICES OF HIGH SCHOOL SOCIAL SCIENCE TEACHERS IN SOCIOECONOMICALLY DIVERSE CLASSROOMS
}

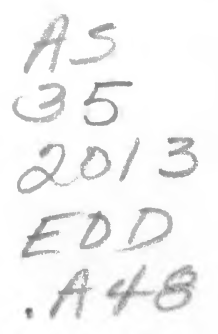

A dissertation submitted to the faculty of

San Francisco State University

in partial fulfillment of the requirements for the Degree

Doctor of Education

In

Educational Leadership

by

Jeffery D. Alves

San Francisco, California

December 2013 
Copyright by

Jeffery D. Alves

2013 


\section{CERTIFICATION OF APPROVAL}

I certify that I have read Technology Practices of High School Social Science Teachers in Socioeconomically Diverse Classrooms by Jeffery D. Alves, and that in my opinion this work meets the criteria for approving a thesis submitted in partial fulfillment of the

requirement for the degree Doctor of Education in Educational Leadership at San Francisco State University.

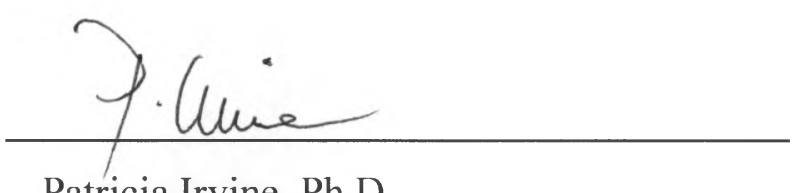

Patricia Irvine, Ph.D.

Associate Dean, Graduate College of

Education

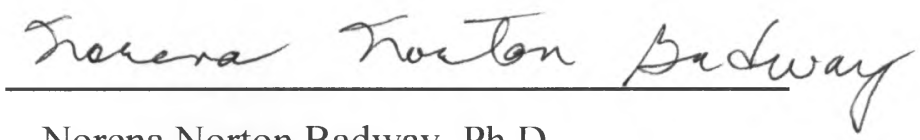

Norena Norton Badway, Ph.D.

Graduate Program Coordinator,

Ed.D. Program in Educational Leadership

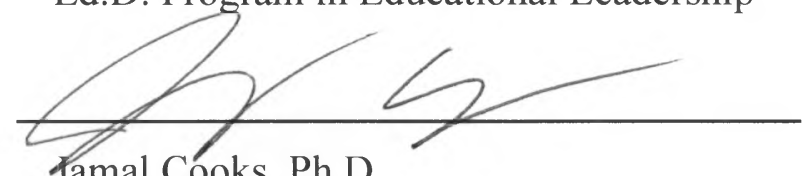

Jamal Cooks, Ph.D.

Assistant Professor, Department of

Secondary Education 


\title{
TECHNOLOGY PRACTICES OF HIGH SCHOOL SOCIAL SCIENCE TEACHERS IN SOCIOECONOMICALLY DIVERSE CLASSROOMS
}

\author{
Jeffery D. Alves \\ San Francisco, California
}

2013

This study of the ways in which social science teachers in low, middle and high SES high schools use technology in their teaching demonstrated that the digital divide is alive and well in the San Francisco Bay Area. A qualitative research design with ten teacher interviews was employed to gain a deeper understanding of their technology use in the classroom. Four main themes emerged from the data. Teachers from lower SES schools used technology to prepare students for standardized tests, while teachers from higher SES schools used technology to prepare students for college and careers. Although teachers from lower SES schools were unable to workaround technological challenges, teachers from the higher SES schools were able to bypass these problems and use technology to enrich students' learning. While teachers of low SES students used technology to distribute information, teachers of higher SES students used technology to embellish students' learning. These technological practices taught low SES students to compartmentalize knowledge, middle SES students to analyze knowledge and high SES students to communicate and collaborate with their peers to create and present knowledge. The acquisition of these skills prepares low SES students for low-level positions, middle SES students for professional positions and high SES students for leadership positions later in life. These findings reveal how differences in technology use across socioeconomically diverse classrooms help to perpetuate social hierarchies and social reproduction.

I certify that the abstract is a correct representation of the content of this dissertation.

P. laie

Chair, Thesis Committee
$12 \cdot 16 \cdot 13$

Date 


\section{TABLE OF CONTENTS}

List of Tables ........................................................................................................... vii

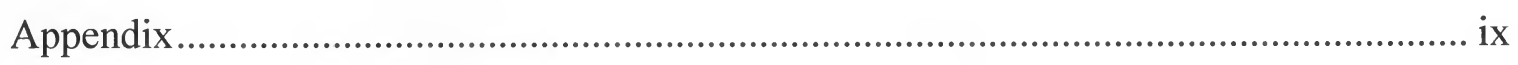

Chapter One: Purpose of the Study ................................................................................

Introduction and Problem Statement .....................................................................

Purpose of the Study ...............................................................................................

Conceptual Framework ......................................................................................6

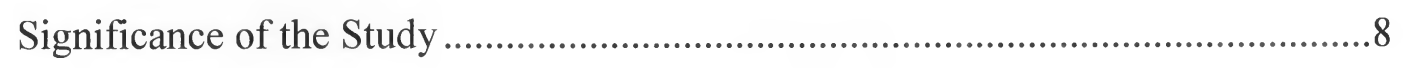

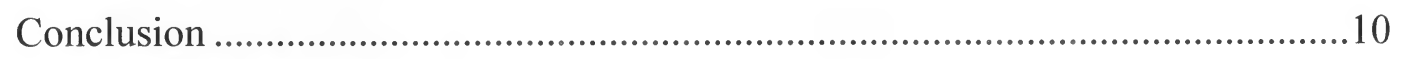

Chapter Two: Literature Review .................................................................................12

Methodology of the Review.................................................................................12

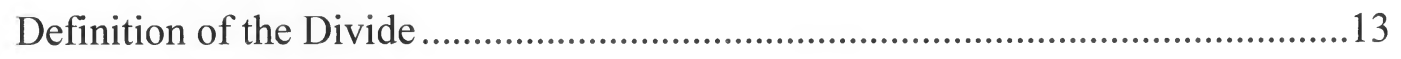

Philosophical Concerns........................................................................................

Extent of the Digital Divide..................................................................................18

Technological Access in Schools.....................................................................18

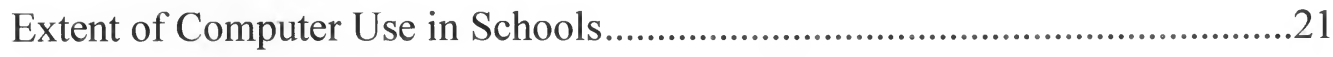

Technology Use in Social Science........................................................................2

Teacher Uses of Technology in Social Science .................................................28

Student Uses of Technology in Social Science.....................................................30

Effects of Social Science Technology Practices on Student Learning .....................32

Test Scores in Social Science ............................................................................32

Engagement and Motivation ...............................................................................3

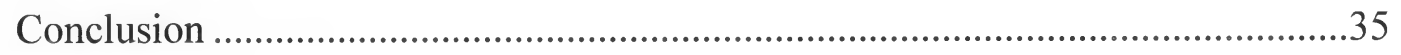


Chapter Three: Methodology of the Review

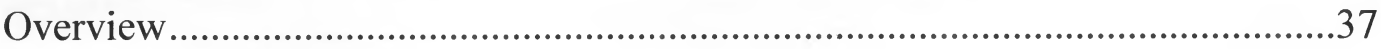

Qualitative Research Design ...........................................................................38

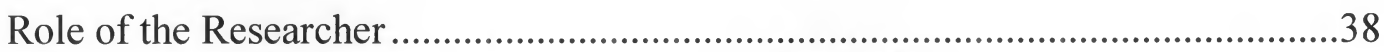

Context and Participant Selection ...............................................................39

Ethics and Protection of Human Subjects...................................................45

Data Collection Procedures.............................................................................46

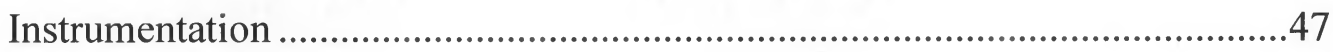

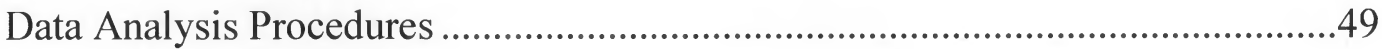

Confirmations, Assumptions and Limitations ...................................................51

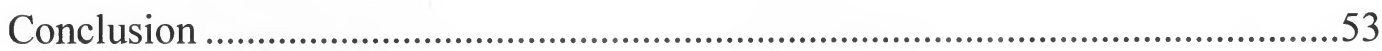

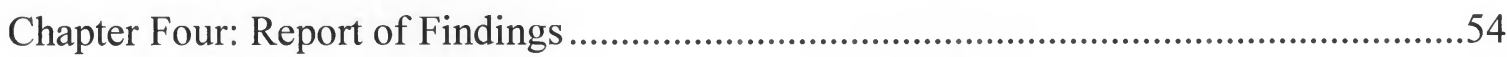

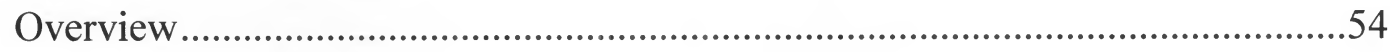

Findings from the Low SES School ............................................................55

Access to Technology in the Low SES School.............................................55

Social Science Teachers' Technological Uses in the Low SES School ..........57

Opportunities for Students to Use Technology in the Classroom....................59

Opportunities for Students to Use Smartphones in the Classroom.................62

Social Science Teachers' Reasons for Limited Student Technology Use ........64

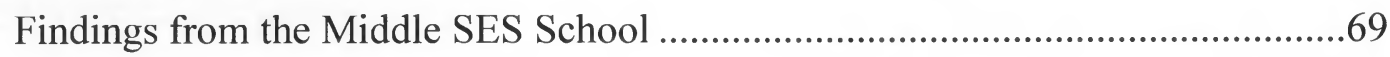

Access to Technology in the Middle SES School .........................................69

Social Science Teachers' Technological Uses in the Middle SES School .......72

Social Science Teachers' Internet Use in the Middle SES School ..................75 
Opportunities for Students to Use Technology in the Classroom........................78

Social Science Teachers' Use of Technology to Prepare for Common Core ...81

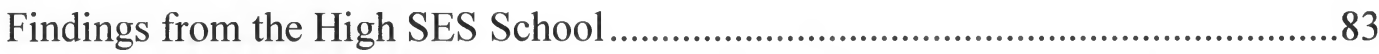

Access to Technology in the High SES School .....................................................83

Social Science Teachers' Technological Uses in the High SES School............86

Facilitating Student Learning Opportunities through Technology .....................89

Opportunities for Students to Use Presentation Software in the Classroom ....91

Opportunities for Students to Use the Internet in the Classroom .......................92

Emergent Themes from the Data ...........................................................................94

Constructing Workarounds for Technological Challenges..................................94

Technology Use for Test Preparation ................................................................98

Teaching Students to Use Technology for Life After High School..................100

Engaging Students through Technology-rich Learning Opportunities............103

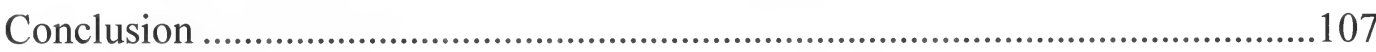

Chapter Five: Discussion and Recommendations.........................................................109

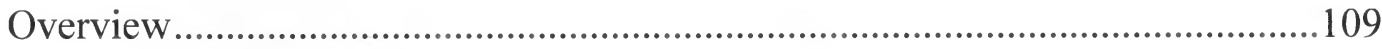

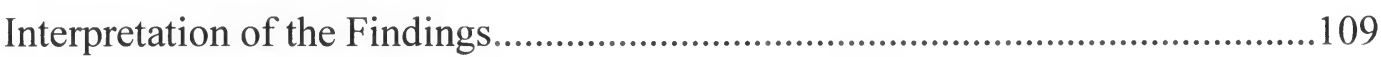

Implications of the Research............................................................................114

Perpetuating Socioeconomic Hierarchies through Technological Learning

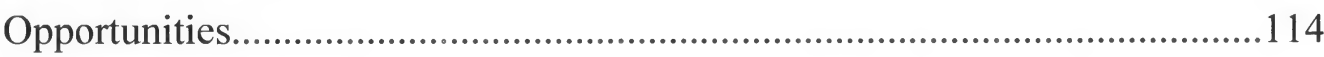

Developing Workarounds to Enrich Students' Learning through

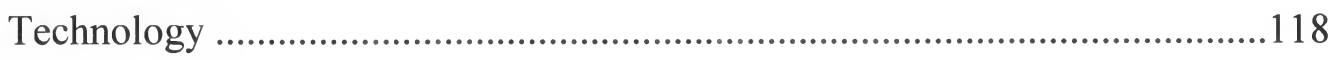

Equity Costs of Current Technological Practices .............................................121

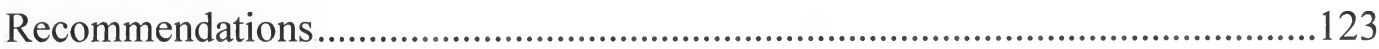


Recommendations for High School Social Science Teachers .123

Recommendations for School Leaders .............................................................125

Recommendations for Policymakers ……......................................................126

Recommendations for Further Study ...............................................................127

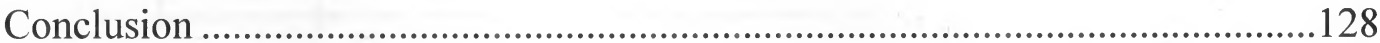

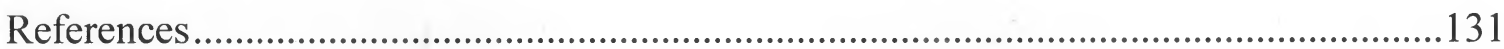

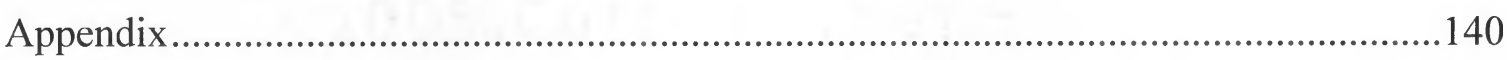

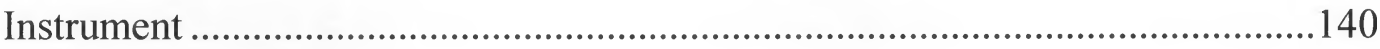




\section{LIST OF TABLES}

Table

Page

1. Selection Process of School Sites........................................................................41

2. Overview of the Participating High Schools ............................................................42

3. Student Demographics of the Participating High Schools ........................................43

4. Social Science Teacher Selection Process...............................................................44

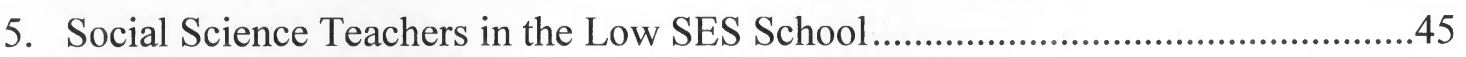

6. Social Science Teachers in the Middle SES School................................................45

7. Social Science Teachers in the High SES School ....................................................46 
APPENDIX

Appendix

Page

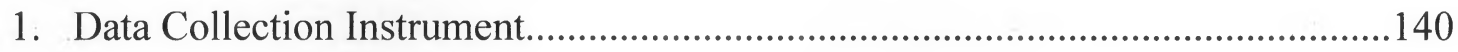




\section{Chapter One: Purpose of the Study \\ Introduction and Problem Statement}

As an August sun steadily crawls over the horizon, parents and students line up at high schools across the San Francisco Bay Area to pick up class schedules, explore the campus and reunite with friends they have not seen all summer. Amongst the myriad of movement, one can see a multitude of students using mobile technology. As incoming freshmen peek glances at the older kids' fashions from beneath dented tablets, sophomores share the latest videos with their friends. Nearby, juniors can be seen tweeting their class schedules and almost instantaneously receiving picture messages from their friends reacting to the news. At the top of the social hierarchy, seniors seem to ignore everyone else and focus on capturing lifelong memories on their smartphones and then posting them to three of their social networks simultaneously. It is clear that high school students are using the latest technological innovations, but what remains unclear is if educators are cognizant of ways to employ equitable uses of technology in socioeconomically diverse social science classrooms. Thus, it is the purpose of this study to discover how social science teachers in the San Francisco Bay Area are actually using technologies in their classrooms.

For social science teachers however, technologies are both advantageous and detrimental to students' learning. On the one hand, the ubiquity of technologies can be seen as an opportunity to incorporate more technology-based activities into the curriculum. Yet, many schools are increasingly ill equipped to meet this goal with an 
aging technological infrastructure, inoperable computers and slow Internet connections. Since students already have access to their own technological devices, more social science teachers may consider utilizing them instead of the school's technologies.

On the other hand, these technologies can be viewed as counterproductive to students' learning. Today's students are torn between participating in class and the broader digital media culture on the Internet (Peck, Mullen, Lashley \& Eldridge, 2011). To some social science teachers, these technologies compete for students' attention and hinder teachers' ability to teach the state-mandated curriculum.

These conflicting perspectives have been exacerbated in an era characterized by high-stakes testing. One of the biggest problems facing education today is the disparity in academic achievement among lower-income, minority and English language learner (ELL) students. The disparity between these students and Asian and Caucasian students has become known as the achievement gap. In 2001, Congress passed the No Child Left Behind (NCLB) Act to address the achievement gap. With its passage began a decade of high-stakes testing, strict accountability and punitive consequences for schools failing to meet their academic performance index (API) goals (Ravitch, 2009). Feeling the pressure of NCLB's corrective consequences, many social science teachers have utilized new technologies to prepare students for the Standardized Testing and Reporting (STAR) assessment (Zhao, 2007; Lipscomb, 2003).

Technology is often viewed as having the ability to provide new solutions to old problems and some social science teachers have had success using technologies to 
improve students' test scores (Frazier, 2009; Heafner \& Friedman, 2009). However, using technology to prepare students for standardized tests has come at the expense of using technology for other learning opportunities. Social science teachers increasingly have to choose which goals to meet through technology use. Although a majority of educators understand the importance of teaching students how to use technologies for academic purposes (Wood \& Howely, 2012), research has shown that they have either been underused (McGlinn, 2007; Anderson \& Becker, 2001) or used for teacher-centered instruction (Johnson, 2011). The difference in technology usage has led researchers to expose a digital divide in social science classrooms across socioeconomic status (SES) (DeWitt, 2007; Warschauer, Knobel \& Stone, 2004).

Although new technologies may hold great potential for enriching students' learning, low SES student populations tend to receive fewer opportunities to use technology compared to higher SES student populations (Banister \& Fischer, 2010). For example, while low SES students tend to use school computers to type, enter data, search the Internet and create multimedia presentations, high SES students tend to be assigned more challenging technology-based activities, like analyzing data they locate online and constructing digital projects and presentations (Booth, 2008; Becker, 2006; Warschauer et al., 2004; Cuban et al., 2001). Though social science teachers understand that limiting low SES students' access and use of technologies widens the divide, many of these teachers continue to restrict students' classroom uses of technology (Peck et al., 2011). While the digital divide in social science classrooms remains, teachers are faced with the 
challenge of using technologies to enrich students' learning opportunities and their professional obligations to prepare them for standardized tests.

With Common Core State Standards (CCSS) replacing NCLB in the 2014/15 school year, social science teachers may feel less pressure to use technologies for direct instruction. CCSS aims to help students cultivate the foundational skills they need to succeed in college and career by stressing students' development and mastery of literacy skills in each content area instead of the memorization of facts. While the social science content standards will remain, CCSS will slow the pace of coverage. Thus, the policy is designed to encourage social science teachers to focus on developing students' literacy, critical thinking and analytical skills.

For some social science teachers, using technology to implement a Common Core curriculum may require a change in their pedagogies. Research has shown that social science teachers understand the benefits of providing students with opportunities to use technologies to develop their literacy skills (Hicks, Doolittle \& Lee, 2004), but that teachers can be unwilling to use technology to accomplish these goals if it requires a change in their pedagogy (McGlinn, 2007). While CCSS may likely slow the pace of coverage and focus on students' acquisition of literacy skills, it does not necessarily mean that social science teachers will equitably use technologies to achieve this goal. On the cusp of this policy transition, this study will reveal the ways in which social science teachers are currently using technologies in the classroom. 


\section{Purpose of the Study}

The purpose of this study is to discover the ways in which social science teachers are using technologies in school communities that differ socioeconomically. The central question of this research study was:

1. How do social science teachers use technologies across socioeconomically diverse classrooms?

Identifying how social science teachers are currently using technologies in the classroom will yield four major insights. Firstly, researching how social science teachers' technology use differs across SES will provide a better understanding of the current state of the digital divide. In the past fifteen years, understanding of the digital divide has evolved and so must research efforts. While prior research has identified different factors that affect students' access and use of technology, such as income level, ethnicity and school location (Becker, 2006; Attewell, 2001), more current research focuses on the specific uses of technology (Harris \& Hofer, 2011; Hohlfeld, Ritzhaupt, Barron \& Kemker, 2008). This study will provide future researchers with a more contemporary depiction of the digital divide's current form in social science classes.

Secondly, this study will uncover the different ways social science teachers are using technologies for teaching and learning. Technologies have become an important tool for many teachers to present course materials and ensure students' learning. These findings will demonstrate how social science teachers across SES use the technologies that are accessible and available to them. 
Thirdly, this research will reveal how students are allowed to use technologies in social science classrooms. Part of social science teachers' technological pedagogies includes the opportunities they create for students to access and use technologies. By analyzing these findings across SES, this study should help to uncover different ways other social science teachers could provide traditionally marginalized student populations with equitable access and use of technologies. With the change from NCLB to CCSS, social science teachers may be starting to provide students with more frequent opportunities to access and use technologies. This study will report the ways in which teachers either encouraged or hindered equitable technology use in their classrooms.

Lastly, this study will help uncover the goals behind how technologies are used by social science teachers. This will provide insight into the motivators that drive the technological practices of social science teachers. These findings will not only reveal differences in teachers' reasons for using technologies in certain ways, but also any inequitable practices across SES.

\section{Conceptual Framework}

In constructing this study, two frames of thought were used. The first framework centered on the digital divide. The digital divide is the name given to the documented occurrence involving the inequitable access to technology and the available and actual uses of these technologies among different groups of students in and out of schools (Banister \& Fischer, 2010, Attewell, 2001). Research has shown that low-income, minority and ELL students receive a lower quality of access and use of technologies than 
higher-income, Asian and Caucasian students. This study seeks to uncover the current state of the digital divide in social science classrooms in the San Francisco Bay Area. The study will ascertain the extent to which these teachers are using technologies and analyze ways in which they foster students' access and use of technologies in the classroom.

The disparity in technological learning opportunities can further separate lowincome, minority and ELL students from their peers. In a time where technology is almost ubiquitous in society, developing students' technological skills and knowledge is essential for their success after high school. Thus, the second framework in this study is social reproduction theory. According to social reproduction theory, the inequitable access and use of technologies for lower-income, minority and ELL students can translate into limited opportunities in their future. Without opportunities to access and use technologies in sophisticated ways, these students may not have the technological skills needed for high-level jobs.

Technology has become the most recent link in a long chain that binds schools and the economy together. Since the late $19^{\text {th }}$ century, American schools expanded this economic relationship by juxtaposing the skills and knowledge they taught with different socioeconomic periods in history, such as periods of industrialization, immigration and war (Bernard \& Mondale, 2001). With the increasing development and distribution of technologies into almost every sector of our economy (Watson, 2006), the next generation of workers will need to be technologically savvy, skilled and innovative in 
order to succeed in this modern society. From 1990 to 2007, the amount of professional and business jobs in California rose nearly 3\%, creating more opportunities for highly skilled workers, while the amount of manufacturing jobs in California decreased by over 6\% (California Faculty Association (CFA), 2009). This economic shift from manufacturing to professional and business jobs will require more training for high-level positions and increased competition for low-skilled positions.

Competition for such low-level jobs is on course to keep increasing among people in the poorest communities (Duncan-Andrade \& Morrell, 2008). Since lower-income, minority and ELL students comprise many of these communities, they are the ones who will face the brunt of this competition. If these students receive a second-class education with limited opportunities to access and use technologies in equitable ways, then they will not be competitive in the workplace. With lower-level skills, these workers will confront the glass ceiling faster than any other group.

\section{Significance of Study}

Conducting this research is important to the field of digital equity education and practitioners across the nation for four main reasons. Research into the digital divide has revealed inequitable learning opportunities for students across SES. This study will determine the extent of this divide among three Bay Area high schools. These school sites will be from lower, middle and upper-income communities to reflect the socioeconomic differences inherent to the digital divide. By analyzing these diverse schools, the range of differences in the technological practices of social science teachers 
will become evident. Thus, this study will expose the current state of inequitable access and use of technologies in Bay Area social science classrooms.

Secondly, this study will identify the various types of technological practices that social science teachers in different SES classrooms used in their teaching. This study will present a realistic portrayal of social science teachers' technological practices in the classroom. Unlike studies where researchers support teachers' integration of technologies for teaching and learning (Banister \& Fischer, 2010; Basham, Meyer \& Perry, 2010), this study examines the technological practices of social science teachers without interference. These public school teachers rely on themselves or other technologically savvy individuals at the school for any questions they have and challenges they encounter. Thus, this sample is representative of other teachers across the country who do not get assistance integrating technology from researchers or professionals from the technology sector.

Thirdly, by understanding how social science teachers are using technologies in their classrooms will help to refine our understanding of the digital divide. Identifying the various types of technological practices of social science teachers will help to recognize ways that these practices perpetuate social hierarchies. Recognizing these uses of technology that reinforce social reproduction can help other social science teachers to stop these classroom practices. Conversely, showing the types of practices that are vital for providing students with higher-level uses of technology will enable these teachers to use technologies to enrich students' learning. Understanding this binary will help 
teachers to provide students with critical uses of technology that help narrow the digital divide and prepare students to succeed in a technology-driven society.

Fourthly, this study will provide educational leaders with a better understanding of how social science teachers can use technologies to create equitable learning opportunities for their students. Having a shared understanding of social science teachers' technological practices, educational leaders can more effectively evaluate teachers' technology usage and provide relevant feedback to them. With this new knowledge, educational leaders will be able to better recognize, evaluate and support teachers in their goal to provide students with equitable learning opportunities through technology.

Lastly, the findings from this study will provide policymakers with an accurate depiction of how social science teachers' technological practices are influenced by educational policies, such as NCLB and CCSS. Since educational leaders create policies to achieve specific goals, these plans and policies could be improved by the findings in this study. Using this data, policymakers could create technology policies that encourage social science teachers to use technologies in ways that enrich students' learning and support digital equity in the classroom.

\section{Conclusion}

After the passage of NCLB in 2001, social science teachers quickly became focused on improving students' test scores. Some social science teachers used technologies to cover a vast amount of content material, while others simply did not use 
technology for teaching and learning. Since the digital divide was exposed in social science, there needs to be broader efforts into researching this disparity and presenting ways to provide all students with equitable opportunities to learn through technology. By conducting this study and disseminating the findings, social science teachers, educational leaders and policymakers will be more informed to enact changes that improve the ways in which technologies are used across SES to enrich students' learning experiences in social science classrooms. 


\section{Chapter Two: Literature Review}

\section{Methodology of the Review}

With schools acquiring an increasing amount of technologies there is a greater opportunity for these resources to be accessed and used equitably inside the classroom. Despite the presumed ubiquity of these technologies, research into the digital divide has shown stark disparities in how they are accessed and used across ethnicity and SES (Banister \& Vannata Reinhart, 2011; Becker, 2006). The purpose of this study is to understand the different ways social science teachers in the San Francisco Bay Area are using the technologies present in their schools. This chapter will review literature pertaining to the nature of the digital divide in public schools and the ways it has been addressed by researchers. The guiding research question for this study was:

1. How do social science teachers use technologies across socioeconomically diverse classrooms?

This chapter begins with a discussion of how researchers have defined the digital divide and the philosophical concerns inherent to this inequity. The next section will examine extent to which the digital divide has impacted teachers' and students' access and use of technologies in schools. The focus will then narrow to how teachers and students have used technologies within social science classrooms. I will then examine the effects that using technology has had on student learning in social science.

Literature for this review was acquired through Education Resources Information Center (ERIC), ProQuest Dissertations and Theses and Google Scholar search engines. 
Initially, the search terms used were extremely broad, such as technology, digital divide and social science. The search terms became increasing narrow to obtain more specific information about the nature and extent of the digital divide, effects of computer use in social science classrooms and advocated practices for improving digital equity in these classrooms. Peer reviewed articles and dissertations were used to construct this literature review. For every source a summary was created depicting the key points of each study. These notes were then analyzed and synthesized for this chapter.

\section{Definition of the Digital Divide}

Over the past 20 years, the digital divide has been increasingly used to convey the different learning experiences students across the nation were having with technology. Literature on this topic generally concludes that minority and lower-income students receive inequitable opportunities to access and use technology for learning. Common themes have arisen from literature on the subject. These themes have progressed from discussing the access and availability of computers and Internet connections to the ways in which these technologies are used by teachers and students.

One of the earliest depictions of the digital divide came at the turn of the century when Attewell (2001) identified the divide as an issue between those who have access to and use of computers and the Internet and those that do not. His seminal article clearly established the first two dimensions of the problem, access and use. As new research into the divide emerged, so did the way in which access was viewed. Becker (2006) suggested that Attewell's (2001) conclusion of the digital divide was too "general" (p.3). 
Becker (2006) moved the definition of the digital divide forward and states that access includes the availability of computers in schools. However, availability does not simply mean having enough computers. The British Educational Communications and Technology Agency (BECTA) (2006) illustrates that the quality of access to technology, especially computers, should also address convenience. The study reasons that teachers' and students' accessibility to technology can improve by having computers in easily accessible locations. Having sufficient numbers of computers is necessary for teachers and students to use them, but the issue of access has been revealed to be more complicated than previously thought.

One of the salient points from Attewell's (2001) work was the technological dichotomy of the haves and have-nots. This binary looks at the problem of access to technology as a quantity issue, one which educational leaders could easily solve by acquiring additional computers. Warschauer and Matuchniak (2010) claim that it is insufficient to view the digital divide as simply between those that have the technology and those that do not. The authors suggest that the divide should be seen for its differing degrees of access and use. Gorski (2005) contends that the different levels of access and use are at the heart of this problem and having equity of access should be the focus for improving technological access in schools. Instead of looking at the problem of the digital divide as one of scalability, these authors have moved the focus from obtaining more computers to equitable ways of using them. Even Attewell (2001) pondered, "whether 'Let them have Pentiums' proves more practical than 'Let them eat cake"" 
(p.257). Later research has shown that this solution in itself was as insufficient for schools across the country as it was for Marie Antoinette.

When the second level of the digital divide is considered, the inequity is seen more clearly. The second dimension of the digital divide deals with the inequitable uses of technology by historically marginalized groups in society like minority and lowincome students (Bryant, 2012; Hohlfeld et al., 2008; Attewell, 2001). Not only does the second level of the divide deal with how computers are used in school, but how often they are used and by which students (Becker, 2006). Hohlfeld et al. (2008) go even further, adding that the degree to which technology is integrated into classroom activities is an important factor regarding technology usage. These claims suggest that if technologies are truly being integrated into the curriculum, then there will be increased usage by teachers and students.

Yet, increased computer access and usage does not necessarily mean they are being used in high-quality ways. For students to be able to harness technology to accomplish this goal, Warschauer and Matuchniak (2010) contest that students should be able to critically assess, analyze and interpret information, construct innovative solutions to complicated problems and collaborate with others to accomplish goals and projects. As a byproduct of using technology in such high-quality ways, Prensky (2008) contends that users will develop "digital wisdom" (p.2). This concept stems from users judiciously leveraging sophisticated technology to make more ethical and rational decisions. Making such decisions through technology requires students to play a greater role in using these 
technologies for their own personal goals. For example, Kim and Kim (2001) claim that students can use technology to empower their decision-making abilities to better achieve their own goals and objectives. Using technology to make such informed decisions that can lead to student empowerment has been identified as the third dimension of the digital divide (Hohlfeld et al., 2008).

\section{Philosophical Concerns}

Since the digital divide has been defined, researchers have expressed two major concerns regarding the disparities discovered in schools. The first concern stems from the theory of social reproduction. In education, social reproductive theory asserts that schools that serve higher-income students prepare them for higher-level jobs while schools that serve lower-income students reinforce their marginalization from such jobs (Finn, 1999). For instance, Seiler, Tobin and Sokolic (2001) found that AfricanAmerican students in urban schools were not provided with sufficient skills and knowledge to prevent their social and economic marginalization after graduation. With trends demonstrating a shift from manual labor positions to higher-skilled positions (CFA, 2009) and an increased use of technology in these jobs (Watson, 2006), skills like critical thinking, interpretation and communication (Levy \& Murnane, 2004) are becoming essential for all workers to have. Thus, students with limited skills, knowledge and abilities face greater competition gaining employment.

Social reproductive theorists also claim that these students face socioeconomic marginalization unless they possess technological skills and knowledge. According to 
Wood and Howley (2012), technology is integrated throughout our economy and those students who develop higher-level technological skills and knowledge will be "rewarded in the labor market" (p. 21). This argument is reminiscent of Attewell's (2001) binary of the haves and have-nots. Students who obtain the necessary technological skills and knowledge in school will be in a better position to gain high-level employment, while students that do not have these skills must compete over lower-level jobs. Thus, minority and low-income students are likely to encounter a significant amount of socioeconomic hardships throughout their lives.

A second issue that arose from the digital divide literature stems from concerns over social justice in schools. As researchers have found low-income and minority students have had less access to and use of technology in school (Banister \& Vannatta Reinhart, 2011; Becker, 2006; Attewell, 2001), they argue that these students develop less technological skills than their peers. This limited access and use of technologies by low-income and minority students has become an equity issue.

For some, limited technological learning opportunities "conjures up images of poor minority youth receiving an inadequate education... later to be refused employment because they are unfamiliar with core technology and skills required for manipulating information" (Attewell, 2001). The ostracism of low-income and minority students from higher levels of technological access and use for skill development is a new form of discrimination. This digital form of segregation not only leads to different skill sets, but 
also illustrates that digital inequities in schools should be addressed as an extension of the social justice movement (Banister \& Vannatta Reinhart, 2011).

\section{Extent of the Digital Divide}

For the past quarter century, there has been a growing body of research into the digital divide. This literature confirms that differences exist in how technology is accessed and used in schools. The disparity in accessing technologies has traditionally been measured by the ratio of total number of students in a school to the amount of computers available for students to use. While measuring equitable computer access is straightforward, measures of usage are more subjective. Though digital inequities have been found to exist along ethnic, geographic, linguistic and gender lines, it has been most noted among SES. Differences in income levels of students and the communities in which they reside have significantly contributed to this inequity. For this reason, this section will discuss measures of the digital divide across SES and the inequities as reported by researchers.

Technological Access in Schools

According to Attewell (2001), technological access refers to the ability to use computers and the Internet. Cuban et al. (2001) note that access to computers and the Internet also should refer to the placement of these technologies in classrooms, computer labs and media centers. Thus, these two definitions are at the root of access to and availability of computers and the Internet within schools. In addition to having computers and Internet access in these locations, Culp, Honey and Mandinach (2005) 
argue that access should include relevant software and Internet content and technical support. Central to these definitions of access is equity. Gorski (2005) argues that all students need equitable access, support and encouragement to use computers and the Internet. It is along this theme of equity that researchers have measured technological access in schools.

Inequitable access to computers was evident by the start of the new millennium. The two most common measures of technological access are student to computer ratios and percentages of Internet connectivity. The NCES (2000) uncovered that schools in high SES communities had an average of 2.5 more computers per students than schools in low SES communities. From 2001 to 2003, Kleiman (2004) reported that schools across the country had increased their spending on computers and other technologies by nearly 25\%. Parsad and Jones (2005) set out to discover how much access to computers and the Internet schools actually had. Looking at over 1,200 schools, the authors found that almost all of these schools had access to the Internet. However, they could not boast the same rates for computer access. Parsad and Jones reported that student to computer ratios had decreased from 12.1 to $4.4: 1$, but schools in low SES communities had higher ratios than schools in high SES communities. Anderson and Becker (2001) investigated the cause for this inequitable spending on hardware, software and technological support in schools. Surveying principals, technology coordinators and teachers from 560 schools across the country, Anderson and Becker concluded that schools in high SES communities outspent schools in low SES communities to acquire and integrate 
technology into the classroom. One of the most interesting findings was that schools in high-income areas spent over $400 \%$ more than schools in low-income areas on technology support personnel for school sites. Parsad and Jones (2005) confirmed this finding citing nearly $45 \%$ of schools in their study could not afford additional personnel to support technology integration. Even when schools in low-income communities did receive training, schools in high-income communities received between $5-23 \%$ more technological support (Gorski, 2005). Though student to computer ratios showed signs of improvement, these studies demonstrate that schools with high SES students have greater access to technologies and the support needed to use them effectively in the classroom.

Differences in computer access are evident in schools that do not have the resources to acquire sufficient quantities of technology. Conducting a wide study across forty states, Becker (2006) investigated the differences in how high-end technologies are distributed, access and used among students from different schools. After analyzing the NAEP 2000 State Mathematics database, interviewing state education technology directors and surveying over 70,000 students, he found significant inequities in the number of computers and quality of use. Becker discovered that students in rural schools had less computer access than students in urban and suburban schools. Six years later, Wood and Howley (2012) confirmed Becker's (2006) findings that students in rural schools had less access to computers and laptops. Surveying over $5003^{\text {rd }}$ grade teachers in Ohio, Wood and Howley (2012) found that for almost all variables, students in affluent suburban schools enjoyed a higher quality of computer access, use and support than their 
peers in rural and urban schools. Thus, schools in urban and rural areas have difficulty keeping up with the technological access, use and support of schools in the more affluent suburbs.

Researchers also wanted to find out if different levels of access existed across students' homes. Looking at over 1,000 students across the nation, Eamon (2004) found that students from high-income households had nearly three times as many computers as students from low-income households. That same year, Warschauer et al. (2004) came to the similar conclusion after surveying teachers and students in eight schools serving low and high SES students in California. The authors confirmed Eamon's (2004) findings that low SES students had less access to home computers than high SES students. While Warschauer et al. (2004) found that computer access at home only differed $15 \%$ between low and high SES students, Internet access between the two groups was much higher. The authors discovered that low SES students had 25\% less Internet access than their high SES peers, which resulted in their teachers not assigning technology-based activities for homework. Consequently, low SES students not only have less access to technologies and the Internet, but also opportunities to use them at home for academic purposes.

Extent of Computer Use in Schools

Most researchers do not provide a precise definition of what technological use actually means. Rather, these authors discuss usage as the extent to which it is applied by teachers and students (Hohlfeld et al., 2008; Cuban et al., 2001). According to Bebell, 
Russell \& O'Dwyer (2004), this "multi-dimensional" (p.49) depiction of technology usage can be measured in two main ways, by the frequency with which it is used or according to the specific software programs or applications used.

Research into the frequency of technology usage has revealed low levels of use in schools. In Northwest Ohio, Muir-Herzig (2003) obtained data on teachers' and students' technology usage by having them rate their level of usage on Likert surveys that ranged from none, rarely, moderate to high. She reported that a majority of the teachers did not use computers frequently in the classroom. Muir-Herzig found that around $15 \%$ of the teachers frequently used computers for mainly didactic instructional activities, such as tutorials and skill building assignments. Hannafin (2008) used more specific measures and asked participants to rate the frequency of their computer usage on a scale from hardly ever, once a month, once a week, a couple of times a week to every day. His analysis of over 2,000 teacher and student surveys revealed that the majority of teachers felt comfortable using computers for completing basic professional and instructional tasks. Despite their familiarity using computers in these ways, they reported infrequent computer use in the classroom. Student data concurred with this finding as $65 \%$ of $8^{\text {th }}$ graders and $50 \%$ of $5^{\text {th }}$ graders stated that they did not use computers frequently in the classroom. While the teachers cited slow Internet connection, insufficient quantities of computers and computer labs that were "inadequate" (p.6), students' computer usage was negatively impacted as a result. 
The students who experience the least amount of access to computers are minority students. Looking at the digital divide in schools across the nation, Becker (2006) found that African-American and Latino students accessed and used computers less than their peers. His research shows that schools with high percentages of these students had limited opportunities to use a computer. However, there are some schools attempting to provide these students with more opportunities to access and use computers. For example, Zucker and Hug (2008) investigated the impact a 1:1 laptop program would have on technology usage. The authors showed that over $80 \%$ of the diverse student body used laptops almost every day in their core classes. While 1:1 laptop initiatives show promise, many schools are not able to afford implementing such a program.

To explain differences in technology usage across schools, some researchers have listed the differences between specific programs used, while others have grouped these differences in themes. For instance, Rowand (2000) reported that many of the ways teachers use technology include lesson planning, gathering and presenting information, constructing student materials, communication, administrative tasks and record keeping. Later studies group specific technological tasks into corresponding themes. Warschauer et al. (2004) consolidated teachers' and students' technology use into themes of performativity, workability and complexity. Harris and Hofer (2006) expanded their categorization of technology usage arguing that technology was a tool used to express knowledge in written, visual, conceptual, product-oriented and participatory forms. More recently, other researchers have claimed that technology could also be leveraged to help 
students accomplish their goals and improve their position in life (Wood \& Howley, 2012; Banister \& Vannatta Reinhart, 2011; Hohlfeld et al., 2008).

One of the core components to many of these studies deals with the quality of technology use. Cuban et al. (2001) state that high-quality uses of technology occur when they are used to make presentations, analyze data and interpret data. Bull and Hammond (2008) argue that quality use involves using technology as a "platform" (p.277) to create, share and remix. Ertmer, Ottenbreit-Leftwich, Sadik, Sendurur and Sendurur (2012) add that quality technology use grants users greater participation, collaboration, problem solving and knowledge development. However, Warschauer (2007) reminds educators that quality technology use also includes access to modern and user-friendly computers, printers, high-speed Internet connections and advanced software programs. The necessity of having access to quality hardware, software and Internet connections demonstrates the symbiotic relationship between access and use for creating high-quality technological learning experiences for students.

Research into technological uses in school reveals that not all students are being exposed to high-quality uses of technology. In Massachusetts, Bebell et al. (2004) surveyed nearly 2,900 teachers and found that a majority of them provided their students with few opportunities to use computers to create projects. However, there are some studies that show low SES students using computers for more than skill building. Warschauer et al. (2004) investigated how having access and use of technologies prepared students in California to enter college. While the authors found low SES 
students in California high schools were using computers to make presentations, their high SES counterparts were using technologies to perform higher-level tasks and produce more creative projects. In Florida, surveys from principals and technology coordinators enabled Hohlfeld et al. (2008) to reveal significant differences in technology usage across SES. The authors found that high SES students used advanced productivity software more than low SES students across all grade levels. These findings illustrate that highSES students are receiving more practice using computers for higher-level skills than low SES students.

The extent to which students use technology in the classroom is largely determined by the ways their teachers use technology. Cuban et al. (2001) found that a majority of teachers in two Silicon Valley high schools had access to computers, but rarely used them. The authors noted that many of the teachers had different pedagogical objectives and felt that computers did not help them meet these goals. Five years later, teachers in schools instructing high SES students were found to provide their students with more access and use of technology than teachers in schools instructing low SES students. Becker (2006) revealed that teachers in schools with predominantly highincome students gave their students $20 \%$ more multimedia-based assignments than teachers in schools with mainly low-income students. Though these teachers were assigning their students more opportunities to use technology, teachers do not always give assignments that are connected to overarching learning goals (Warschauer et al., 2004). Wenglinsky (2006) states that the amount of technological learning opportunities 
students receive is completely up to how their teachers decide to use it in the classroom. Therefore, the ways in which teachers decide to use technologies in the classroom has a direct impact on their students' education.

There have been varying reports about levels of teachers' technology use. Bebell et al. (2004) found that a majority of teachers were using computers for lesson planning, emailing and grading. While the authors did find moderate levels of teachers using technology for instructional purposes, over 30\% of teachers never used computers to present their curriculum. Rakes, Fields and Cox (2006) investigated connections between teachers' technology use, skills and instructional practices. Like Bebell et al. (2004), they found that teachers had some technological skills, but used technologies moderately for instruction. However, differences were found between survey and interview data. When surveyed, teachers claimed they used technologies to create constructivist lessons. Yet, when interviewed, these same teachers were unable to provide details of any such lessons. Despite their inability to describe the ways they used technologies for constructivist purposes, there are other groups of teachers who demonstrated higher levels of technology use. Hohlfeld et al. (2008) discovered a trend in Florida public schools that an increasing amount of teachers used technologies to present their curriculum. However, conditions of the digital divide still exist as teachers in schools with mostly high SES students demonstrated higher levels of technology use than teachers in schools with mostly low SES students. 


\section{Technology Use in Social Science}

Early studies have shown that digital inequities also exist in social science. Anderson and Becker (2001) discovered that social science teachers used technology less than all other core subject teachers. Even when other studies demonstrated higher numbers of social science teachers using technology, this data was skewed by a few individuals who used technology while the majority of their colleagues did not (Cuban et al., 2001). Hicks et al. (2004) revealed despite recognizing the benefit of having students use technology to analyze web-based primary sources, the majority of social science teachers he interviewed chose not to incorporate this technological practice in their curriculum.

Other studies show that more social science teachers have begun using technology. However, differences across SES arose. Warschauer et al. (2004) found students at low and high SES school communities using computers to conduct Internet searches and complete projects. However, students in the affluent schools engaged in more high-quality research and analysis with technology than students in the non-affluent schools. DeWitt (2007) found that higher SES students receive greater computer access and use than low SES students. Teachers at schools with predominantly high SES students provide their students with more time to use computers in class, in technology centers and at home to complete a variety of computer-based assignments. 
Teacher Uses of Technology in Social Science

Although social science teachers are slowly integrating technologies into their pedagogies, they are mainly using it for direct instruction rather than student-centered activities. According to Johnson (2011), PowerPoint has become a common presentation software used by a majority of high school social science teachers. He found that nearly $60 \%$ of teachers used it three or more times a week even though nearly $65 \%$ of students preferred moderate PowerPoint usage. While a majority of students stated that they liked the use of audio and visuals in power points for learning, they disliked that "it was not interactive and that it was boring" (p.79). Kennedy (2010) also discovered evidence of $12^{\text {th }}$ graders wanting to use teachers' technology in their social science classrooms. Observing four social science teachers, she reports that teachers monopolized the use of their interactive whiteboards for the purposes of showing Word documents, PowerPoints, videos and images and to conduct Internet searches. Students expressed an interest to take control of their own learning through technology and argued "the school should be spending money on adding more computers for student use since this was what they would be encountering more frequently after graduation" (p.46). Although students clearly articulated the desire to use interactive technologies, the majority of teachers used their technologies in teacher-centered ways.

When social science teachers dominate the use of technology in the classroom, they limit students' opportunities to interact with these technologies. McGlinn (2007) argued that teacher-centered practices of displaying information are merely basic uses of 
technology. She explains that more innovative uses of technologies involve learning activities where the students are using technologies to complete assignments and projects. Based on her interviews with nine social science teachers who attended a summer technology and writing institute, McGlinn (2007) found that they had the ability to use technologies in more innovative ways. However, for teachers to employ more studentcentered technology activities requires a willingness to try nontraditional instructional styles. Despite students' desire to use technology (Kennedy, 2010), some social science teachers were in favor of prohibiting students' opportunities to use technology if it meant they could retain their established pedagogies (McGlinn, 2007).

Zhao (2007) found that the reason why many social science teachers do not facilitate student-centered technology lessons is due to "the pressure of time constraints and excessive curricular coverage" (p.318). Without additional class time for students to complete technology-based assignments, these teachers were hesitant to try more studentcentered activities. Even award winning social science teachers feel these pressures. Lipscomb (2003) interviewed three such social science teachers and found that they believed "technology was just a tool to supplement learning" (p.216). Notwithstanding their exemplary status, these teachers primarily used technologies to prepare students to pass standardized tests. Social science teachers feel such demands reinforce the use of teacher-centered technological practices in the classroom. 


\section{Student Uses of Technology in Social Science}

Although student-centered technology practices have not been adopted by all teachers, there are some examples of how students are using technology in social science classrooms. Elementary and secondary students have been recorded using technology for word processing and Internet searchers. In elementary school, Booth (2008) found that $4^{\text {th }}$ and $5^{\text {th }}$ grade students infrequently used technology in class for social studies, but used computers for writing and editing. Students stated that they liked using computers for these purposes because "technology made writing and revisions easier and faster" (p.85). In high school, Cuban et al. (2001) observed that when high school students did use computers in social science classes, they were used for word processing and Internet searching. Warschauer et al. (2004) and Lowther, Ross and Morrison (2003) argue that using the Internet to conduct social science research helps students develop problemsolving skills. Based on a three-year laptop implementation program, they found that students with 1:1 access to laptops used their laptops for Internet research more frequently than students using laptops off a mobile cart. Students with 1:1 laptop access engaged in more historical inquiry and scored higher on a social science problem-solving test than their peers using the mobile laptop carts. Internet research can also allow students to discuss problems. Bryant (2010) illustrated that a group of minority students in a school that educated mainly low SES students can build and strengthen their literacies through engaging in Internet research and analysis of debate topics. 
Studies have also shown students using computers to complete more creative projects in social science. Warschauer et al. (2004) discovered that schools that served mostly low SES students used computers to create more PowerPoint and video presentations than schools that served mainly high SES students. Hofer and Swan (2009) illustrated how $6^{\text {th }}$ grade students in ELA and social studies core classrooms could successfully create historical documentaries by working collaboratively on both their storyboards and video production.

Other research illustrates the challenges associated with providing students class time to complete projects and presentations on computers. DeWitt (2007) found that social science teachers in schools that served mostly low SES students felt overburdened presenting the state-mandated content standards. This pressure to cover the material limited low SES students' opportunities to construct projects and presentations on computers.

However, there are studies that demonstrate ways in which social science teachers have provided students access and use of technologies outside of the normal classroom period. Bryant (2010) found that an after school program allowed low SES students to investigate controversial topics and make presentations on the subject matter. Basham et al. (2010) showed that urban high school students created historical videos using footage taken on a field trip to a museum. Although these cases are limited to only a few classrooms, they demonstrate creative ways in which social science teachers could provide students with time to use technologies. 


\section{Effects of Social Science Technology Practices on Student Learning}

Research into the technology practices in social science has revealed proximal and distal outcomes for student learning. When measuring the benefit of such technological practices, researchers typically discuss the effects of student learning in terms of test scores, engagement and motivation.

\section{Test Scores in Social Science}

Standardized assessments have become an increasingly important component of education and classroom learning. Although math and ELA are held more accountable than any other subject, social science teachers have felt pressure to prepare students for standardized tests. For example, Lipscomb (2003) demonstrated that even exemplary social science teachers believed that the best use of technology was to help students improve their test scores. Other researchers have set out to determine the extent to which using technologies in social science classrooms has on test scores. Lowther et al. (2003) found that by providing students with 1:1 laptop access they could do better on social science writing and problem solving assessments than students with less access. Frazier (2009) found that seniors in an urban Virginian high school who enrolled in a technology education program outperformed the control group by nearly forty mean points.

However, not all studies demonstrated such promising results. Lively (2010) found mixed results among $4^{\text {th }}$ and $5^{\text {th }}$ graders using computers to take social studies assessments. The author discovered that students using this system had better scores than the control group in economics and history. Yet, these students showed no improvement 
in civics and a decrease in achievement in geography and core skills. Heafner and Friedman (2008) found that having $11^{\text {th }}$ grade students to use computers to create electronic scrapbooks did not improve students' test scores. Despite this finding, students claimed that they had a better understanding of the historical material using technology to complete the assignment. Due to this qualitative data, Heafner and Friedman (2008) repeated their experiment eight months later with fewer students. The second experiment resulted in students reporting the same retention and understanding of the material and performing higher than the control group on the social science unit test. The results from these studies demonstrate the inconsistencies of using technology to improve students' achievement on social science assessments.

\section{Engagement and Motivation}

Researchers also look at non-quantitative ways to evaluate the effects of technology on student learning in social science classrooms. Two common measures of this are engagement and motivation. Doppen (2004) investigated these themes in four social science classrooms. He found that teachers' technology practices helped students to understand the different perspectives for historical events. Though students claimed to be more engaged in social science lessons when using computers and the Internet, Doppen (2004) found mixed results. While he observed some students engaged in the technology-based assignments, he witnessed others socializing instead. However, other studies have shown that when students have more individualized access to computers, engagement increases. For example, Schleicher (2011) looked into the impact a 1:1 
netbook initiative had on student engagement and learning. He found that $86 \%$ of students felt engaged in learning activities when they were able to use netbooks. Although students claimed that using technology increased their engagement, productivity and learning, quantitative data showed a slight decrease in these areas.

Bryant's (2011) research also describes higher levels of student engagement when students have greater access to computers. Looking into the technology practices of an after school debate team in a school with predominantly low SES students, she found students extremely motivated to work with computers because they rarely did so in class. Bryant (2010) discovered high levels of student engagement in the technology assignments because of the perceived relevancy of the subject matter to the students. Due to this meaningful access and use of computers, students proclaimed a newfound confidence in using this technology. However, being motivated to use computers does not necessarily mean that students have the skills to complete their assignments. While students expressed their confidence using computers, assessment data revealed their limited ability to operate computers. For example, poor spelling affected successful Internet searches and only $22 \%$ of students knew how to use Spell Check to correct their spelling mistakes.

Sustaining student engagement in technology-based social science activities can be challenging. While prior research shows that student engagement and motivation increase when students use computers, students can also lose interest in technology-based assignments. Despite a high percentage of student engagement, Schleicher (2011) states 
that three teachers observed students' engagement in social science lessons decreased as the "novelty and interest in using the netbooks diminished" (p.138). Quantitative data also supports the teachers' claim, as student surveys articulated a slight decrease in their engagement after using the netbooks. Doppen's (2004) findings illustrate another challenge social science teachers had getting their students to complete technology-based assignments. While these teachers were able to get students to understand multiple perspectives surrounding historical events, they had a hard time getting students to engage in independent historical inquiry. These findings add another layer to the effectiveness of technology to engage and motivate students in social science.

\section{Conclusion}

The inequities caused by the digital divide are extensive. They have impacted the access and use of technologies by teachers as well as students. Although schools have adopted more technologies, it is not being accessed and used in the same ways across SES. Teachers and students in schools located in high-income communities continue to show benefits of accessing and using technologies in higher-quality ways than teachers and students in schools located in low-income communities. The same has held true for teachers and students in social science. However, researchers have investigated how teachers in schools that serve predominantly low SES students can narrow the divide and improve the use of technology in social science classrooms. Though some of these studies are limited to a single school or classroom, they stand as advocated practices that can be utilized in other social science classrooms around the nation. 
This study will focus on the San Francisco Bay Area and determine if the digital divide is thriving or if teachers of low SES students are working to improve the access and use of technologies in their classrooms. The following chapter will present a description of the methods used to gather, analyze and report data from this study. 
Chapter Three: Methodology

\section{Overview}

The purpose of this study was to reveal the technology uses employed by social science teachers from different high schools. This chapter provides a detailed description of the qualitative research design for this study. Since this study sought to understand the ways in which social science teachers use technologies inside their classrooms, an indepth qualitative research design was constructed. Selecting a high-tech area of California offered promising insights into the technological practices of social science teachers. A total of ten social science teachers from three high schools in the San Francisco Bay Area participated in this study. The data were collected during face-toface interviews and recorded and transcribed for accuracy. One interview was conducted over the phone and not recorded to honor the wishes of that participating teacher. However, copious notes were taken with that teacher's permission. All of the data were analyzed and categorized into themes that were relevant to answering the research question.

The following sections of this chapter lay out the qualitative design structure of the study, research questions and role in conducting this research. Afterwards, the researcher provides an explanation of the selection process for participating schools, an overview of these schools and the steps taken to protect these individuals. The chapter culminates with descriptions regarding how the data was collected and analyzed. 


\section{Qualitative Research Design}

This study was a vehicle for developing a better understanding of how social science teachers use technologies in the classroom. To develop insight into how social science teachers use technology, conducting a qualitative methodology enabled me to analyze the layered complexities of this research topic (Butin, 2010). The guiding question for this research study was:

1. How do social science teachers use technologies across socioeconomically diverse classrooms?

This research question is conceptually rooted in the digital divide. Since the digital divide has been shown to exist between higher and lower-income communities, the researcher will select three schools in different socioeconomic communities for study. The main data collection tool used to gather the in-depth data needed to answer these research questions is through face-to-face interviews. The researcher will derive relevant themes from the data that will answer the research question and then be categorized and later reported (Creswell, 2002). Constructing this qualitative design methodology enabled the researcher to analyze the complex nature of how these social science teachers are using technologies in their everyday work environments (Marshall \& Rossman, 2011).

\section{Role of the Researcher}

My role in this study was to research how high school social science teachers in socioeconomically diverse communities use technologies in their classrooms. Through 
my selection process, I narrowed my sample down to three high schools in the Bay Area. One of the sample sites I was already familiar with. Prior to conducting this research, I had met the social science teachers who worked in the school that served mainly low SES students. As a social science teacher who also worked with low SES students, I recognize the importance for accurately recording and reporting the data from each participant. All of my interviews were conducted ethically and digitally recorded and transcribed for accuracy. Despite my acquaintance with the teachers in the school that educated low SES students, no information was reported that could help to identify who they are. All names, places and other personal information were altered to protect these individuals. While I did not know the other social science teachers at the schools who predominantly served middle and high SES students, the same principles were applied to their persons. All of the data was then analyzed and reported in Chapter Four of this dissertation.

\section{Context and Participant Selection}

To set the stage for discovering how social science teachers in San Francisco Bay Area high schools use technologies in their classrooms, the following section process explains the rationale for choosing the school sites and participants.

The first step in my selection process was to choose only public high schools in the San Francisco Bay Area for study. Limiting the study to the Bay Area allowed for interviews to be conducted at local school sites. Since I would have to travel to each school site to interview the social science teachers, selecting a centralized location would 
enable me to effectively and efficiently conduct the research. Limiting the study to public schools eliminated academy, charter, continuation, magnet and private schools due to the uniqueness of each individual school and the various differences in schools' visions, objectives and structures. After excluding these schools, sixty-two public high schools remained.

Secondly, I categorized the students that attended these schools by SES. To identify schools that predominantly served low, middle and high SES students, I determined SES by the percentage of a school's population in the federal Free/Reduced Price Meal (FRPM) program. The FRPM program was used to determine SES because it is the federal government's guide for providing financial assistance to students from lowincome households. Selecting schools that served mainly low, middle and high SES students mirrors the digital divide research that has demonstrated inequities across SES.

Potential school sites were then categorized by the SES of the students enrolled in those schools. Schools that served predominantly high SES students were those identified as having between $0-15 \%$ of their student body on the FRMP. Schools that served mostly middle SES students were classified as having between $16-35 \%$ of their student body on the FRMP. Lastly, schools were classified as serving low SES students if the school had more than $35 \%$ of their student body on the FRMP.

Thirdly, I selected schools that not only had a school website, but online documents to allow for broader data collection strategies. These digital documents provided specific information about the kinds of technology each school had, their 
student to computer ratios, age of technological infrastructure, type of access to the Internet, etc. Having this information helped describe the technological landscape of the schools, as well as create and contextualize interview questions for social science teachers. This step narrowed my sample size from sixty-two schools to thirty.

Lastly, I began emailing the principals of these ten schools to determine if I could potentially conduct research at that particular school. While two principals agreed to allow me to conduct research at their schools, the remaining principals did not respond to my emails. At that point, I began cold calling the remaining eight principals and received permission from one more principal to conduct my study at their school. The remaining principals either did not respond to emails and phone calls or declined to participate.

Thus, a sample size of three socioeconomically diverse high schools was finally obtained.

The following table depicts the selection process described above.

Table 1: Selection Process of School Sites

\begin{tabular}{|l|l|l|l|l|}
\hline Selection Factors & Low & Middle & High & Total \\
\hline Public High Schools in SF Bay Area & 30 & 19 & 13 & 62 \\
\hline $\begin{array}{l}\text { Online Access to Technology } \\
\text { Infrastructure }\end{array}$ & 16 & 6 & 8 & 30 \\
\hline $\begin{array}{l}\text { Centrally Located Schools for } \\
\text { Sampling }\end{array}$ & 3 & 4 & 3 & 10 \\
\hline $\begin{array}{l}\text { Schools Contacted to Participate in } \\
\text { Study }\end{array}$ & 3 & 4 & 3 & 10 \\
\hline $\begin{array}{l}\text { Schools that Volunteered to } \\
\text { Participate in Study }\end{array}$ & 1 & 1 & 1 & 3 \\
\hline
\end{tabular}

Table 2 and Table 3 below provide a description of the participating schools' enrollment, API, SES, student to computer ratios and student demographics. Table 2 illustrates that the schools not only serve students from socioeconomically diverse 
communities, but their achievement also varies from low to high. The school serving low SES students had the lowest API scores and the school serving high SES students had the highest API scores.

Table 2: Overview of the Participating High Schools

\begin{tabular}{|l|l|l|l|l|}
\hline School & $\begin{array}{l}\mathbf{2 0 1 1 - 1 2} \\
\text { Enrollment }\end{array}$ & API & $\begin{array}{l}\text { FRMP \% of } \\
\text { enrollment }\end{array}$ & $\begin{array}{l}\text { HS Student: } \\
\text { Computer Ratio }\end{array}$ \\
\hline Low & 1,924 & 751 & 44.5 & $3: 1$ \\
\hline Middle & 2,924 & 825 & 21.9 & $17.2: 1$ \\
\hline High & 2,212 & 951 & 3.9 & $3.8: 1$ \\
\hline
\end{tabular}

Table 3 below displays demographic data for the students at each of the three participating high schools. The low SES school served a majority of Latino students (44\%) and a smaller group of Caucasian students (19\%). The middle SES school had a majority of Caucasian students (34\%) with similar percentages of Asian (24\%) and Latino students (22\%). The high SES school worked with a predominantly Asian student population (85\%). The next largest demographic was Caucasian students $(11 \%)$.

However, both the low (19\%) and middle (34\%) SES schools had larger percentages of Caucasian students than the high (11\%) school.

While low and middle SES schools had approximately the same percentages of African American students $(\approx 7 \%)$, there were very few African American students at the high SES school $(<1 \%)$. The high SES school also had very few Latino $(2 \%)$ and Pacific Islander students (2\%). The low SES school had the largest populations of Pacific Islander (10\%) and ELL students (9\%) and the smallest number of Asian students (13\%) out of the three schools. 
Table 3: Student Demographics of the Participating High Schools

\begin{tabular}{|l|l|l|l|l|l|l|l|l|}
\hline School & $\begin{array}{l}\text { \% } \\
\text { Asian }\end{array}$ & $\begin{array}{l}\% \\
\text { African- } \\
\text { American }\end{array}$ & $\begin{array}{l}\text { \% } \\
\text { Caucasian }\end{array}$ & $\begin{array}{l}\text { \% } \\
\text { Latino }\end{array}$ & $\begin{array}{l}\text { \% Native } \\
\text { American }\end{array}$ & $\begin{array}{l}\text { \% } \\
\text { Pacific } \\
\text { Islander }\end{array}$ & $\begin{array}{l}\text { \% } \\
\text { Other }\end{array}$ & $\begin{array}{l}\text { \%LL } \\
\text { ELL }\end{array}$ \\
\hline Low & 12.7 & 7.1 & 19.1 & 44.4 & 0.3 & 10.4 & 3.6 & 9.3 \\
\hline Middle & 24 & 6.6 & 33.5 & 22.4 & 0.2 & 2.6 & 10.3 & 3.3 \\
\hline High & 84.8 & 0.6 & 10.6 & 2.0 & 0.1 & 1.7 & 0.1 & 3.5 \\
\hline
\end{tabular}

After receiving permission to conduct research at each of the three school sites, I emailed every teacher in the social science departments to inform them about the purpose of my study and ask if they would be willing to participate. From the forty-six emails I sent to these teachers, I received responses from ten teachers who volunteered to participate in the study. I then set up interviews with teachers at each school site who expressed a willingness to discuss their technology practices with me. This small, but distinct sample of teachers at each site helped me obtain a diverse sample that would supply multiple perspectives on the complexities (Creswell, 2002) of technology use at each school. By selecting and conducting interviews with these teachers, I obtained a new depth of understanding (Patton, 2002) regarding how their technology practices differed.

The following table illustrates how many social science teachers volunteered to participate in this study compared to the amount of teachers in the each respective department. 
Table 4: Social Science Teacher Selection Process

\begin{tabular}{|l|l|l|}
\hline $\begin{array}{l}\text { Participating } \\
\text { Schools }\end{array}$ & $\begin{array}{l}\text { Number of Teachers } \\
\text { Emailed }\end{array}$ & $\begin{array}{l}\text { Number of Teachers who } \\
\text { Volunteered to Participate }\end{array}$ \\
\hline Low & 11 & 4 \\
\hline Middle & 20 & 3 \\
\hline High & 15 & 3 \\
\hline
\end{tabular}

Tables 5-7 provide a closer look at the social science teachers in schools that served mainly low, middle and high SES students. There were an equal number of male and female participants in the study. However, the majority of these teachers were Caucasian. The school instructing predominantly high SES students employed the only two non-Caucasian teachers, which were of Asian and Indian descent.

Additionally, teachers at these school sites had varying years of teaching experience. In the school instructing mainly low SES students, three out of the four participating teachers had twenty or more years teaching experience. In the school that instructed mostly middle SES students, one teacher had more than twenty years teaching experience while the remaining two teachers had taught less than ten years. In the school with high SES students, two of the three teachers had about twenty years teaching experience and the remaining teacher had taught for more than ten years. In short, all of the participating teachers were highly experienced. 
Table 5: Social Science Teachers in the Low SES School

\begin{tabular}{|l|l|l|l|l|}
\hline Teacher & Gender & Ethnicity & Subjects Taught & $\begin{array}{l}\text { Years } \\
\text { Teaching }\end{array}$ \\
\hline Mr. Ackerman & Male & Caucasian & US History & $>20$ \\
\hline Mrs. Cook & Female & Caucasian & World History & $\approx 20$ \\
\hline Mr. Costa & Male & Caucasian & US History & $\approx 20$ \\
\hline Ms. Giannino & Female & Caucasian & $\begin{array}{l}\text { US History, Government, } \\
\text { Economics }\end{array}$ & $<10$ \\
\hline
\end{tabular}

Table 6: Social Science Teachers in the Middle SES School

\begin{tabular}{|l|l|l|l|l|}
\hline Teacher & Gender & Ethnicity & Subjects Taught & $\begin{array}{l}\text { Years } \\
\text { Teaching }\end{array}$ \\
\hline Mr. Bartolo & Male & Caucasian & US History, Economics & $\approx 10$ \\
\hline Mr. Green & Male & Caucasian & World History & $\approx 10$ \\
\hline Mrs. Perry & Female & Caucasian & $\begin{array}{l}\text { US History, World } \\
\text { History }\end{array}$ & $>20$ \\
\hline
\end{tabular}

Table 7: Social Science Teachers in the High SES School

\begin{tabular}{|l|l|l|l|l|}
\hline Teacher & Gender & Ethnicity & Subjects Taught & $\begin{array}{l}\text { Years } \\
\text { Teaching }\end{array}$ \\
\hline Mr. Beckham & Male & Caucasian & Government, Economics & $\approx 20$ \\
\hline Mrs. Hsu & Female & Asian & US History, Economics & $>10$ \\
\hline Mrs. Karishma & Female & Indian & $\begin{array}{l}\text { World History, Ethnic } \\
\text { Studies }\end{array}$ & $\approx 20$ \\
\hline
\end{tabular}

\section{Ethics and Protection of Human Subjects}

My role in this study was to organize the methodology for conducting research in an ethical manner to protect all participants. According to Johannesen, Valde and Whedbee (2008), incorporating ethics into a study requires an observance of the principles of right and wrong human behavior. During the course of this study, I 
interacted with each participant in a morally appropriate manner to ensure the study was conducted with integrity. I was morally sensitive (Johannesen et al., 2008) to the contexts, situations and interactions that might have affected the participants and used empathy to obviate any ill affect. Just as teachers have the power to create a successful learning environment through positive language (Fasset \& Warren, 2004), researchers have a similar ability. During my interactions with these participants, I built a trusting relationship through my language and tone that was professional and friendly (Roth \& Tobin, 2009). Furthermore, all participants were informed that the study was voluntary and that would not result in financial reimbursement, but there may be a contribution to the overall understanding about how technologies are currently being used in the classroom. After the data collection, I ensured the anonymity of the participants and their school sites by changing each of their names to a pseudonym. Through these measures, I have ensured the ethical treatment and protection of the educators who participated in this study.

\section{Data Collection Procedures}

During 2013, three high schools compromised of low, middle and high SES students in the Bay Area were selected to participate in this study. Once I had been granted permission to conduct research within each of these schools, I performed two phases of data collection for this study. The first phase began when I went on to the schools' websites and gathered data relevant to the schools' technological infrastructure. 
This data provided evidence of the types of technologies that were claimed to be accessible and available to social science teachers.

Following this digital document review, I solicited information by conducting interviews with social science teachers. I contacted all of the teachers in the three social science departments via email to determine which teachers were willing to participate in the study. In each participating school site, three to four teachers were interviewed about how they use technologies in their classrooms. All of the interviews were conducted face-to-face inside the teachers' classrooms, with the exception of one phone interview. By interviewing these teachers, I gained a more robust understanding of how technologies were actually being used in the classroom. For example, interviewing these social science teachers elicited information about how they viewed the purposes behind their technology use and its applications in the classroom. This interview data was essential in uncovering differences that exist in the classroom technology practices of teachers across SES.

Instrumentation

In each participating school district, interviews were conducted with social science teachers to uncover how technologies are used in their classrooms. By interviewing these teachers at three different school sites, a variety of responses were obtained (Creswell, 2002) regarding their understanding and application of technology in the classroom. Interviewing was selected as the main form of data collection because it 
enabled the extraction of qualitative information, perspectives and experiences (Stake, 2010) from the actual technology users.

Before conducting face-to-face interviews, open-ended questions were created as a general guide to follow during the interviews. The framework for the interview questions came directly from the research questions and the literature review. The questions stemmed from the researcher's goal to find out the current state of social science teachers' technological practices across SES. This interview framework allowed for flexibility in its design, sequence or omission of questions depending on each participant's responses. During the interviews, it was important to recognize the direction of the interviewees' answers and tailor the sequence of questions to their responses. In addition, follow up questions were asked to encourage the interviewees to elaborate on their perspectives, experiences and opinions (Marshall \& Rossman, 2011). While the researcher may have asked each person similar questions from a preconceived list, depending on their responses, the researcher may have chosen different follow-up questions to elicit emic responses (Stake, 2010).

During the interviews, the researcher asked the social science teachers openended questions that allowed the participants to explain how technologies were used for teaching and learning. Through this line of questioning, participants were able to freely articulate and elaborate on their responses (Creswell, 2002), in contrast to close-ended questions that may not allow for varied responses. After starting with an open-ended question, follow up questions asked to gain further clarity about the interviewee's 
answers. This flexibility permitted the interviewees to explore a related tangent that might not have been foreseen if the researcher chose to follow a precise sequence of questions. Though portions of the interviews were unstructured, the flexibility around the participants' responses worked to establish trust during the interview (Marshall \& Rossman, 2011). Taking the time to develop trust with the participants helped them feel comfortable sharing pertinent information that accurately and honestly revealed their experiences and perspectives (Dubin, 2006). By conducting these interviews in a comfortable and open manner, participants were able to go into as much detail about their technology uses as they wanted.

\section{Data Analysis Procedures}

After completing the data collection, I engaged in several steps to accurately code the data. I began this process by transcribing the recorded interviews verbatim and then reading through the transcripts to get a general sense of the data. During these readings, copious notes were taken and important text highlighted and underlined to assist future reviews. Once the open coding process was initiated, I identified and labeled several categories pertinent to the study (Stake, 2010).

Second, the selected text and categories were then be compiled and organized in different matrices, which were created with the 2011 version of Microsoft Word. By organizing the data in this manner, it assisted my examination of the identified topics for similarities and differences. The matrices were stored in digital databases for continued analysis and interpretation. 
Third, the organized data were analyzed and examined numerous times to group the data and formulate themes (Creswell, 2002). Axial coding of the data also helped me to continue clustering the codes together according to similar patterns as they became present in the data (Marshall \& Rossman, 2011), thereby narrowing down the number of themes. As this coding process continued, I reorganized the text, categories and themes according to the patterns that emerged (Marshall \& Rossman, 2011).

Fourth, I conducted an additional scan for any redundancies in the codes and collapsed the findings into corresponding themes (Creswell, 2002). At this point, wall charts and graphic organizers were constructed to determine the relevance and accuracy of the existing themes and categories (Stake, 2010). The classification of the final categories were grounded in the accumulated and analyzed data (Marshall \& Rossman, 2011) that broadly represented the multiple stories and perspectives of the participants. This process concluded with an interpretation of the findings by comparing the results to the literature and formulating a unique perspective from the data.

After analyzing, coding and interpreting the data, I presented the findings of this study in a narrative form. The narrative of these findings are contained in Chapter Four of this dissertation, as well as the final themes that were established from coding the data. Chapter Four reports on the findings from each of the three high schools and explains the participants' technological usage and the underlying motivators for using technologies in such ways. While the results are presented in narrative form, the chapter also includes pithy excerpts from the interviews that illustrate the main themes from the data. 


\section{Confirmation, Assumptions and Limitations}

The findings of this study were derived from the participants' responses during the interviews, which were assumed to be truthful and thorough. The credibility of the participants' responses were confirmed by digitally recording the interviews that ensured verbatim transcriptions of the conversations. In one interview, the social science teacher did not wish to be recorded. With permission of this teacher copious notes were taken and then transcribed directly following the interview.

Conducting interviews as the main form of data collection can be challenging. While participants are granted anonymity, some individuals may not feel completely comfortable sharing certain information that may be seen as negative, controversial or unsuccessful (Dubin, 2006). Accounting for this challenge, it was my goal to build trust from the very beginning of my interactions with each participating teacher to foster a comfortable interviewing environment where participants felt comfortable to openly and honestly answer the questions.

In choosing to conduct interviews as the primary instrument of data collection, an initial bias was established. For example, preparing a list of questions based on teachers' use of available technologies illustrated a bias in my efforts to study these variables. To decrease this bias, follow-up questions were drawn upon to increase participants' ability to express any emic issues about their technology practices, perspectives and purposes. I also attempted to eliminate any potential bias through scrutinizing and reevaluating the data numerous times (Stake, 2010) to account for accurate findings and conclusions. 
The data was confirmed by comparing it against verbatim transcripts, notes taken during the interviews, site documents and the different steps I took to accurately code the data (Creswell, 2002). To further ensure the validity of the findings, the data were corroborated by obtaining data on school websites and from the participating social science teachers. For example, the interview data were validated with evidence from the different documents obtained at the district level. Additionally, the interview data were confirmed against each other to create accurate themes about how social science teachers use technologies in the classroom.

With all qualitative research there are concerns about developing generalizable themes from inferences. While inferences were present in the teachers' descriptions of their technology use and the researcher's interpretation of this data, similar clusters of information surfaced and was accurately coded using previously discussed steps. Since all behavior can be generalized (Bogdan \& Biklen, 2007), the researcher reported the themes that emerged. The generalizations found in this study are reported thematically in Chapter Four.

Despite these steps to reduce bias and increase validity, the study still has certain limitations. Some may view the sample size of the study as too small, as numerous public, private and charter schools in the Bay Area were not included in the data collection. However, since this is a qualitative study, a smaller sample size provides the in-depth look into differences amongst teachers' technology practices across SES. Thus, 
the study provides an accurate qualitative representation of how social science teachers use technologies in the classroom.

\section{Conclusion}

This chapter described the factors of a qualitative study that were used to uncover the technology practices of social science teachers. Three high schools in the Bay Area in socioeconomically different communities were selected for study. In each school, three to four social science teachers were interviewed. Interviews were selected as the main form of data collection to elicit emic responses from the social science teachers about their daily uses of technology. The collected data helped reveal social science teachers' beliefs about the relevance of technology in their curriculum, its applications in the classroom and support received to use technology in these ways. Collecting this interview data facilitated the increase of knowledge about the extent to which technology practices of social science teachers differ across SES. Data collected from district level documents and interviews with social science teachers is discussed in the following chapter. 


\section{Chapter 4: Report of Findings}

\section{Overview}

This chapter presents the research findings and provides an analysis of the data obtained in this study. The purpose of the study was to analyze how social science teachers in socioeconomically diverse communities use technologies in the classroom. This qualitative study employed an exploratory research methodology that was designed to obtain this data. Three high schools in the San Francisco Bay Area were selected to participate in this study. From these socioeconomically diverse schools, a total of ten social science teachers participated in interviews. Participants were interviewed and all identifiable information was changed to protect their anonymity. The findings in this chapter are presented to answer the following research question:

1. How do high school social science teachers use technologies across socioeconomically diverse classrooms?

The qualitative data results in this chapter are presented along SES, beginning with teachers in the school that served predominantly low SES students and concluding with teachers in the school that served mainly high SES students. As a result of the data analysis, themes arose among each school setting. Teachers' technology use in the low SES classroom was characterized by limited technology usage. Teachers of middle SES students used technology to display a variety of digital resources that would engage the students in the academic content material. The teachers in the high SES classroom 
utilized technology to provide students with high levels of access to technology for academic purposes.

Findings from the Low SES School

Access to Technology in the Low SES School

In all four interviews, the social science teachers agreed that they had access to hardware, software and the Internet in their classrooms. All four teachers stated that they either had a desktop or laptop computer and a LCD projector in their classrooms. Out of these teachers, Ms. Giannino had obtained new technological devices. "What I got from DonorsChoose (donorschoose.org) were two tablets and a multi-function printer." Ms. Giannino and Mr. Ackerman also stated that they had digital document cameras. While the other teachers did not report having these devices, they did have more computers than Ms. Giannino. The veteran teachers all had two laptop computers. Mr. Costa said that teachers had one newer laptop and one old computer or laptop. He explained, "It's one of those things where the school district occasionally rolls out newer laptops." Mrs. Cook seemed to benefit the most from these adoption cycles, as she had accumulated three computers and two laptops in her time at the school.

Though the low SES school reported a 3:1 student to computer ratio, there were varying levels of access in computer labs and social science classrooms. Mrs. Cook was the only social science teacher who had student computers in her classroom. However, this put the access ratio in her classroom at 11:1. The school also had three computer labs that teachers can schedule time in, but Mrs. Cook did not have a favorable opinion of 
those computers. When discussing the one of the labs, she said, "There's only ten computers in there. There's more physical computers (in the lab), but they are broken and the working ones are slow." She also tried to use a mobile laptop cart, but said it took nearly $60 \%$ of class time to set them up. Mrs. Cook expressed that neither the computers in the lab or on the mobile cart provided her students with viable options to access computers. Therefore, she chose to let students use the computers in her classroom when needed.

The teachers explained that insufficient funding had impacted their access to technology. Mr. Ackerman chided the educational leaders' attempts to improve the technological infrastructure at the school. "There's no money. The school doesn't have access to any funds to do things like that. I even had to mount my own projector to the ceiling." Mr. Costa added that the school spent limited amounts of money to procure new technologies, making it difficult to provide teachers with even the most basic school supplies. He said, "We're lucky to get poster paper. We really are." He explained that the school's practice had been to, "basically replace what is unfixable. It's not like they (the school district) rolls out a new one (computer) every so many years and use the old ones for the kids. It's nothing like that."

Additionally, the school did not procure Wi-Fi for the teachers or students. However, the school reported having Ethernet connections in every classroom for teachers to access the Internet. Although the school did not provide Wi-Fi, Mrs. Cook stated, "I'm not a tech guru and don't feel like I need Wi-Fi because we have Ethernet 
and that's dependable enough." The other social science teachers did not complain about not being able to access Wi-Fi and expressed that the school's Ethernet connection was reliable.

Social Science Teachers' Technological Uses in the Low SES School

The teachers described conventional technology uses. They reported using laptops, LCD projectors and presentation software to display daily agendas, images and lectures. Three of the four teachers used these presentation programs daily to present information to their students, while Mrs. Cook claimed to use the program the least. $\mathrm{Mr}$. Ackerman and Ms. Giannino lectured daily, while Mr. Costa and Mrs. Cook tended to lecture between two and three times a week.

The teachers used presentation software to lecture and ensure that students wrote down the lecture notes word for word. Mrs. Giannino used PowerPoint lectures daily in her College Placement (CP) Government and Economics classes to emulate college lecture courses. Mr. Costa believed that students "need notes. They need to understand how to take notes and they need to know how to not just write down the information, but hear what I say and put the information down." Mrs. Cook explained why she lectures at least twice a week.

Not all the kids can learn that way, but there's enough kids who still want that instruction. That's why I continue to give that instruction. Sometimes when I completely go away from it, the kids are like, 'You need to go back and do that (PowerPoint lecture) because I couldn't understand all that stuff.' They read it all, did it all, but weren't able to make the connections. 
While Mr. Ackerman lectured daily with Keynote, his students were not allowed to copy down his notes word for word. He believed notes are "a list of things to remember and a record of what took place." Due to this philosophy, his students were required to "take notes on everything that takes place. They have to take notes in their own words. They have to have notes for everything." He was the only teacher who required students to paraphrase his notes.

Though these uses of technology were teacher-based, Mrs. Giannino admitted that this was not her original intent.

From day one that I've been here, all of my teacher credential courses (in college) would tell me that what I'm doing is not right. I wanted to do projectbased learning and student-based learning, but it's just not doable.

She went on to explain,

The goal was always to have them pre-read so we can just have discussions about the stuff and have me fill in the gaps with PowerPoint. In the years that I've taught this, none of my students have done the work (chapter readings) ahead of time. Ever.

Three out of the four social science teachers interspersed additional material into their presentations to support their lecture notes. Mr. Ackerman, Mr. Costa and Ms. Giannino began their presentations with the agenda displayed on the projection screen. Mr. Ackerman and Ms. Giannino followed up with lecture notes, but also liked to incorporate multimedia into their presentations. Ms. Giannino explained that the videos were used "to help students understand the notes." To help his students process the notes, Mr. Ackerman interposed questions in his lectures "to get them to think about what they have learned." In Mr. Costa's PowerPoint lectures, he began by showing students 
historical quotes from controversial figures. For instance, during his World War II unit, he used these quotes to "get across to them (his students) that these holocausts, these genocides, these ethnic cleansings... they keep changing the name so it doesn't sound the same as what happened in the 1930 s and 40 s."

The teachers reported trying to take advantage of other technologies, but stated they were not able to sustain new technological practices. For example, while Mr. Ackerman expressed an interest to use his document camera more in class, he was unable to get it to work properly. He explained that "it would be intermittent in function. The document would sometimes be in focus and sometimes not. Sometimes bright and sometimes dim." Mrs. Cook also expressed frustration when trying to use computers in the lab. Each year, she tries to schedule time in the computer lab so that her students can create a PowerPoint presentation. She said her teaching goals were stifled by inoperable and slow computers. Those frustrations using technology led to their limited or non-use. Opportunities for Students to Use Technology in the Classroom

The social science teachers at Union High School expressed that there were few opportunities for students to use technologies in class. While Mr. Ackerman did not have any lessons where students use technology, the other three teachers assigned students one PowerPoint project.

As part of a history museum project, Mr. Costa allowed students to choose the way in which they presented their final product. Their task was to research a topic that they were interested in and compile and present 100 facts and pictures about that subject. 
Instead of printing out all 100 facts and pictures, he endorsed using PowerPoint as an "environmentally friendly" way to present historical material.

Mrs. Cook gave students the opportunity to create a PowerPoint because she believed

it's nice for them to see the professionalism and what it looks like when your produce something like that. I think it's a practical skill. Every professional I know makes PowerPoints. You need to be able to communicate ideas that way.

Despite her limited technological skills, she taught her students how to do PowerPoint basics, such as "how to set up a slide, how to do bullet points, how to insert pictures into the text, how to change fonts." In addition to teaching basic PowerPoint skills, Mrs. Cook tried to teach her students how to presient.

My rules for them are to limit the number of words. I usually give them a number to shoot for because when you're presenting you want to say something more than what's on your slide. You don't want to read your slide because that's not a good presentation.

In contrast to the presentations assigned by the other teachers, Ms. Giannino paired students together "to present a political issue, like gun control or the Patriot Act, with PowerPoint" once during the semester. For "Topic Tuesdays," her CP Government students presented notes on an issue and showed a song or video on the subject. She required that students "teach both sides (of a political issue) so kids can make up their own minds" about the issues. Since doing this project, Ms. Giannino reported mixed results in terms of students' technology use.

In her first example, she mused that students essentially copied her PowerPoint presentation format. Her expectations were for students to "use any format that they 
choose... but also do something different." She explained that students typically began presenting "the information first. Then they'll show a pro video and a con video." However, she was amused by the similarities between the students' presentations and her presentations. "One class even did a PowerPoint that was kind of like mine. It had videos, ideas and questions in it... which I thought was interesting because they complain when they have to do stuff." While she acknowledged student complaints about her PowerPoint lectures, she argued, "This is their time to shut up and put up and they did the same thing. So it's kind of funny."

In her second example, students surpassed her expectations. However, it was the juxtaposition of presented material that impressed her and not the technology usage.

When we did censorship, they showed what a song's lyrics were. Uncut, uncensored, everything. Which I got permission for from the principal because it was horrific... They (two student presenters) showed the different ways to censor things. The kids thought it was really interesting. They led an activity in which you wrote normal school speak and then they let you do a dirty version to show kids you don't have to use bad words to say what you mean.

Ms. Giannino liked how these students were able to connect the academic subject material to students' interests. She even used this presentation to interject college and career advice. Capitalizing on students' interest in the subject, she segued into a teachable moment. She stated,

We really believe the kids should be able to read, write and speak eloquently... I teach them about code switching. I tell them things like this is what you would say. 'You probably know it as - and then I'll use the slang term - but we're in a classroom, so we refer to this as this. 
Since students only created one PowerPoint in her class, she saw this opportunity to use technology as "their time to shine."

In addition to using PowerPoint, Mr. Costa had his students use technology to complete an interview project. Over Thanksgiving break, students interviewed an older relative or family friend who immigrated to America. Students recorded, transcribed and wrote a one page summary of the interview. He admitted that "it takes them a long time to type because some of these kids can't type without their thumbs." However, the purpose of Mr. Costa's assignment was not to type, but allow students the opportunity to be a historian. He said,

I'm from the standpoint that social studies or the oral part of history is dying as an art form and as we move further in our technology we are losing that whole idea of communicating with one another. We've become very much self-centered with text-centered phones and losing the contact between generation to generation. It's something that gives the kids the chance to connect with another generation.

\section{Opportunities for Students to Use Smartphones in the Classroom}

While students at Union High School have few opportunities to use technologies in their social science classes, the teachers reported students demonstrated a desire to use their smartphones in class. Mrs. Cook stated that students complained about not being able to use slow and inoperable computers in the library. As a result, she let them use their smartphones "as long as students are doing work." Allowing her students to use phones during instructional time was "a slow adjustment for me. I'm kind of a rules person, so it was tough for me to have rules with shades of gray." As she bent her rules 
against cell phones in the classroom, she began allowing ELD students to "use their phones for translation purposes" and absent students to "take a photo of the notes."

Ms. Giannino also allowed students to use their smartphones in class, but in a limited capacity. At the beginning of class, students were encouraged to save all due dates and deadlines in their phone's calendar. While she gave students "two minutes to enter this information," she expressed frustration at not being able to control students" actions on the Internet once their phones were out. She warned her students, "If I see you texting... it's mine. I'll take it from you." Her frustrations were better seen through her experience attempting to utilize Twitter in the classroom.

Ms. Giannino participated in a Public Broadcasting Service (PBS) technology training to use Twitter for classroom warm-ups. She wanted to use Twitter to show "an article with either a video or some sort of interview that went around some idea" and have students post responses using their smartphones. Two major problems arose during her Twitter pilot. First, the activity took more time than planned. She discovered that the reason was due to students texting friends before responding to the prompts. She complained that her seniors gave her excuses to receive more time to text and then complete the assignment.

The second problem happened when she was absent. During her absence, Ms. Giannino assigned a Twitter assignment for the students to do. Instead of doing the assignment, her students convinced the substitute to give them the test ahead of time. 
The students took pictures of several tests and posted them on Twitter. Once again, she expressed her frustrations with integrating technology into the classroom.

That kind of stuff was really aggravating. I didn't like being a warden. If I wanted to be a warden, I would have been a warden. I'd make more money and have a better retirement. But that's not what I want to do. That kind of factor of the technology really pisses me off.

Social Science Teachers' Reasons for Limited Student Technology Use

The social science teachers at Union High School provided students with few opportunities to use technology in class. Three major reasons arose during the data analysis. Firstly, the teachers felt an enormous burden to cover all of California's standards for social science before the STAR test. Mr. Costa summarized the situation.

With STAR testing happening in May, you have to jet through the year. We have to literary fly. You can't just stop and smell the roses on a particular assignment because you just don't have the time. If you don't keep cooking, you're not going to get the last thirty or forty years of history. If you're going to be judged on that, if there are questions on that, what do you do?

When he used PowerPoint, it helped him to maintain this pace. "It (PowerPoint)

helps us to stay focused on the main priority to get our kids' test scores to increase."

Mrs. Cook also felt the pressure to cover vast amounts of content before the

STAR test.

I take it (STAR) seriously because I have a pretty good track record of my students doing very well and I want that to continue. ... I want them to feel that when they leave my class, they got the best education they can get.

However, she acknowledged that the focus on testing had come at the cost of using technology more frequently in class. Instead of providing students with more opportunities to use PowerPoint or their smartphones, she said that she spent a lot of time 
re-teaching concepts. For instance, in her World History class only "one out of thirty kids knows the difference between Austria and Australia."

Nowhere was the pressure more evident than in Ms. Giannino's AP US History class. Due to the overwhelming content material she was required to cover in her AP class, technology was not used in the classroom. This included all technology use from her PowerPoint lectures to the showing movies. She declared,

I have not been able to find a way to integrate it (technology) and get done with the material we need to. That's the problem. We have to go through forty-four chapters. We do two chapters a week and each chapter is more than thirty pages. So literary, I lecture... all of the time.

With or without technology, these teacher-centered practices have led to mixed results for the social science department. Although the department boasted the highest STAR test scores in the school, they paid a price to earn this title. Ms. Giannino shared that the department "did take a hit for that on our WASC visit last year. They said that we do not differentiate instruction enough." The teachers' inability to differentiate instruction stemmed from the pressure of working at a low-performing school. All of the teachers agreed that increasing test scores was a priority. The teachers lectured as the main method to transfer information to their students to maintain improving scores on the STAR test.

There were other factors that limited the use of technology. Mr. Costa shared one such experience that disrupted his class to the point where he could not finish his PowerPoint lecture. 
One of my old students from previous years, he had smoked something he shouldn't have. He wasn't in the right state of mind. He thought his mind was actually going to explode. He came into my class and he's tripping out. The kids were like deer in headlights.

Mr. Costa made sure school leaders took the student to a local hospital to get the medical help he needed. However, this incident halted his presentation.

After that's over, I get in front of the class and say, 'Hey. How about that Industrial Revolution?' How do you teach after some kind of event like that? It's one of those things where you have to go with the flow and just roll with the punches.

The second factor that contributed to students' limited technological experiences dealt with how teachers discovered students were actually using it. As discussed earlier, only two out of the four teachers at Union High School allowed students to use their smartphones in class. Mrs. Cook reported that she "no longer fights it all the time." She allowed students to use their smartphones to translate words and take pictures of lecture notes if absent. Despite these allowances, she was hesitant about how students would use it.

I worry about that they're doing it (taking pictures) for every single assignment. Like they're not going to get that they can do that (take pictures of lecture notes when absent) when I say they can do that, but they can't do that for homework and tests. We have to protect our exam. We know it happens. Somebody's test got out and it got all over campus.

Despite tests having been posted online, Mrs. Cook said, "The funny thing is that they don't know how to cheat properly. They didn't study the test enough to pass it.

They still didn't know what the answers were, just what the questions were." 
Mrs. Cook's concern about students' academic honesty arose from past events of dishonesty. She acknowledged that cheating and plagiarism had happened in her classroom. She discovered that her students had copied because

the kids told me that the questions in the book are evidently all online because they post them. Some of the kids are to the point where (they say), 'Sometimes the answers are too good so I make them sound dumber so the teacher will think they're mine.'

Due to this, she stopped accepting typed assignments. "I've had situations where a student will do an assignment and then they'll just email it out to their friends, change the name and turn it in."

The same behavior was observed by Ms. Giannino in her AP courses. Although Ms. Giannino wanted to incorporate technology into her AP courses, she did not trust her students to do the work on their own. She stated that past problems with students using the Internet to copy notes and plagiarize sources led her to eliminating technology use form the course altogether.

However, she did defend her students. Ms. Giannino explained, "A lot of it has to do with their schedule. They don't have enough time. They don't have time to do their work, which makes me lecture."

Despite limiting students' access and use of technology at Union High School, students found ways to use their smartphones to access the Internet wirelessly. Mrs. Cook admitted, "We have issues on this campus with wireless." Mrs. Giannino added, "We don't have wireless anyway, but some kids actually bring their own routers and plug them into the walls when teachers aren't looking." She motioned to the numerous orange 
Ethernet plugs wrapped around her classroom that connected to the school's Internet server. She continued,

Any kid who sits right there I can't see because their body's in the way, so they could literary plug in. It's not happened to me, but kids have told me that they do it. I've seen them do it, but I'm like, 'Hell no. Not in my class.' That's not happening.

While some teachers have tried to discourage students from accessing the Ethernet ports by covering the faceplates, Mrs. Giannino stated that they "have teachers who put tape in front of all of them and that doesn't deter them. They'll go right through the tape."

Students' determination to use technology also manifested into another problem for teachers at the school. Ms. Giannino revealed that theft and vandalism of technology had plagued Union High School for the past several years.

As for our technology being safe, that's a really big problem. We've had a ton of teachers get their laptops stolen. Even the ones the school gave them. Teacher and student laptops they bought for classes that need computer access and projectors. We kind of have a mixed relationship with technology because at any time it might be taken from you.

Ms. Giannino admitted that students have stolen cell phones and other electronic devices belonging to teachers, students and substitutes. For this reason, she hid the location of her newly donated tablets so that students did not steal them.

In addition to worrying about whether or not her technology was safe, Ms.

Giannino guarded against students vandalizing her technological infrastructure.

I pay attention so that wouldn't happen to me. For instance, things by the door, we have kids cut the phone lines to our classes on a regular basis. They have a 
knife or scissors and they'll cut the phone line because they think it's funny or unplug the phone line or grab something on the way out.

Mrs. Cook had first-hand experience with students vandalizing her technological infrastructure. The school had installed numerous Ethernet access ports in her classroom. Since these ports were openly accessible to everyone, she reported,

We teach teenagers and there's gum in them (the Ethernet ports). It's hard to keep track of. For example, I shared my classroom for four years in a row, so it wasn't even like I could police it. People were in and out. They're using our classroom on the weekends, so nothing is really secure.

\section{Findings from the Middle SES School}

\section{Access to Technology in the Middle SES School}

In the middle SES school, the three teachers reported that they had access to technology in the form of hardware, software and Internet connectivity. The school had also recently set up Wi-Fi. Much of the technological changes in the school were due to hiring a new technology director. According to Mr. McHugh, he "has really been a breath of fresh air" because he has installed Wi-Fi all over the school and allowed teachers to access the entire Internet via an override. Mr. Bartolo was pleased with the change because he "no longer has to run a 100' extension cord from the Internet connection to my laptop and stand it up in the middle of the room to watch a video or show an image."

The school reported having a 17.5:1 student to computer ratio. While all three teachers said they each had a department-issued laptop, Mrs. Perry was the only teacher who had student computers in her classroom. With three computers positioned around 
her classroom for student use, her access ratio of 11:1 was better than the school's ratio. Though she has more student computers in her classroom than the school's average and other teachers in her department, the computers were all over ten years old. She pointed out,

You can see how old that computer there is. One of my own kids had that in high school or college. This doesn't have a USB (Universal Serial Bus) drive. It has a floppy drive, although there's no such thing as a floppy disc anymore.

Despite being slow, Mrs. Perry kept the computers so that students could complete typing assignments and Internet searches in class.

Though Mr. Bartolo and Mr. McHugh did not have student computers in their classrooms, they were familiar with the computer labs on campus that provided students with 1:1 access. According to Mr. McHugh,

One lab is about four years old. Another is about ten years old and has been slowly upgraded and another lab, who knows how old it is, and it sort of works and sort of doesn't. It's basically a last resort if the others are taken.

Both teachers scheduled time in the lab periodically throughout the school year. Mr. McHugh scheduled visits to the computer labs about once a month and Mr. Bartolo used the computer lab around five times during each semester. Accessing the labs had been challenging for both men. Mr. Bartolo explained that when he signed on to the school website to schedule lab time

the labs are barely available. It's one of those things that's hit or miss with the labs. For a school with almost 3,000 kids and you've got three labs, you just can't get your class in there. 
The challenge securing lab time has forced Mr. Bartolo to scale back on the number of times he took his class to the computer lab.

In addition to scheduling conflicts, there were other problems accessing the lab computers. Mr. McHugh revealed that the problem with all the labs was that our labs historically do not have enough functioning computers. There's thirtyfive computers in the labs, but if you have a class of thirty-five students and two of the computers don't function or one doesn't print, it can be very stressful.

Another problem was that not all students could log on to the computers. Mr.

McHugh explained,

The students have to log in with their name and password, but a lot of students don't know these. Students who come in the middle of the year aren't signed in and authorized for the Internet and they can't use the computers. It just makes it painful where you could be in your class having them write an essay on a piece of paper.

After discovering these problems, Mr. McHugh did not plan for computer-based lessons that took multiple days to complete.

Although the school did not have any mobile computer carts, they recently acquired mobile tablet carts. The carts were part of a pilot program at the school and only accessible by a few teachers. All three teachers in this study expressed an interest in using the carts as soon as the pilot program was over. Mr. McHugh stated that many of the teachers in the social science department had been anxiously waiting to use the tablets. "I don't have access to the iPads. I'm not part of the pilot program, but that's been two years now. We're wondering when it is going to be our turn." 
The teachers found other ways to access new technologies. Mr. McHugh explained, "Technology has historically been funded by departments. The different departments have varying levels of technology." Since the school does not regularly purchase technology for the entire school, the department sought other sources to fund their technological needs. He stated that they obtained new printers, scanners and LCD projectors from donations on DonorsChoose and funds obtained by completing the California Healthy Kids survey.

Despite acquiring these technologies, the teachers expressed the problem with obtaining technology at different times. Mr. McHugh said, "The challenge is that... we have a bunch of different models... and things aren't interchangeable.". Having different makes and models meant that the department had to keep track of several different technological devices, each with their own operating systems, replacement parts and operability. One of the best examples of this was Mrs. Perry's old Hewlett Packard (HP) printer. She stated, "You can see how old that printer is. Also from my own kids' younger days. The youngest is twenty-eight. The old HP printers lasted forever. Now printers aren't so good anymore." Though she preferred the older printers for their durability, finding replacement parts and ink cartridges for the old HP printer was difficult.

Social Science Teachers' Technological Uses in the Middle SES School

The social science teachers at Lincoln High School used their laptops and LCD projectors on a daily basis. Mr. McHugh viewed the LCD projector as "the single most 
important piece of technology. Without the projector, the other things would fall apart." Teachers used their projectors to present a variety of information. Based on the interview data, the teachers used PowerPoint to display lecture notes, primary source documents, photographs, artwork, videos, political cartoons, maps and charts.

The teachers reported having basic PowerPoint skills. Mr. Bartolo explained that he followed "basic PowerPoint principles." He said,

I don't have too much writing on one slide. I keep the PowerPoint structured in a way that they (students) get the typical note-taking, Roman numeral structures. I use the themes and have the material shoot in and I try to have visuals that match the material.

During his lectures, he limited the amount of notes students were required to take by giving them a piece of paper with most of the lecture notes printed on there. Rather than have students spend most of the class taking notes, he wanted them "listening and learning." He explained, “There's a lot of material I need to cover and I don't necessarily want to spend half an hour of class just having the kids writing."

Mr. Bartolo utilized themes and characters from popular movies, television shows and books that students were familiar with and inserted them into his lectures. Some of his past themes include Twilight, Star Wars and Pokémon. He argued that his presentations "catch the kids' eye and has the kids more interested." He employed the characters to help students understand major concepts in social science. Mr. Bartolo explained the structure of his most recent thematic presentation.

My last one I just did was on taxes, your basic tax structures and government spending. The theme was Harry Potter. Harry Potter is popping up. Hermoine is popping up. All those characters are popping up talking about taxes and 
spending. Then I have the kids be the characters. It sounds silly because it's high school, but I'm telling you, you give a kid that usually is asleep a character, they're instantly awake. They're taking notes. Kids get into it.

The other goal Mr. Bartolo had for his thematic presentations was engaging students in learning the content material. He described how he accomplished this goal.

What the Mean Girls are actually talking about is the subject. That PowerPoint is 'Intro to Economics and Economic Systems.' When the Mean Girls are inserted, they are talking about that. They're talking about how hot a mixed market economy is. They're connecting it to the material.

While Mr. Bartolo said making these presentations can be quite time consuming, he argued that students were more engaged in the lessons and learning the content material than in traditional lectures.

Mr. McHugh had a different approach to PowerPoint presentations. He stated,

If I go back five years, I was lecturing two to three times a week for most of the period. But I found the shorter the PowerPoint, the bigger the punch. Then I get them to apply it.

During that time, he limited the frequency of his lectures, shortened his lectures to ten or fifteen minutes and increased time for students to analyze and apply historical concepts. He explained the reason behind streamlining his presentations. "PowerPoints are so much more common now and in the beginning, I think I could get away with it because no other teachers had projectors and huge screens." As the novelty of PowerPoint wore off, Mr. McHugh planned for more student-centered learning activities in the classroom. "I feel that the more I teach, the more I go back to old school teaching methods and moving away from how I was trained to teach (in college credential programs)." Instead of presenting the material in a stand and deliver fashion, Mr. 
McHugh liked placing students in "mixed ability groups" to discuss the material and complete worksheets and writing assignments.

Mrs. Perry also used PowerPoint to provide students with lecture notes. Since the department was "very coverage driven," her lectures covered a vast amount of material. She reported using the program in simplistic ways and did not use "all the bells and whistles in PowerPoint." Instead of using PowerPoint for "fancy" animations and slide transitions, she emphasized that her presentations were "all about the images. People, archival photographs, maps, charts. Things like that to go with the text."

Mrs. Perry displayed these digital images to elicit "students' responses to artwork, political cartoons or murals. Just put it up there and give the kids the chance to look closely and say what they see and talk about symbolism and things like that." This analysis and discussion was typically done with the whole class, but she occasionally placed students into small groups.

Mrs. Perry also wanted to use the school's iPads to make the activity more engaging for students. "Ideally... in the future at some point, there would be a set of tablets so that each group or person would have their own." She argued that using the tablets would give her students the ability to analyze the images more closely at their desks, but she cannot check them out until the iPad pilot concludes at the end of the year. Social Science Teachers' Internet Use in the Middle SES School

The teachers at Lincoln High School used the Internet for educational purposes. As previously stated, all of the teachers displayed digital images in their presentations 
that matched the content material. Since the school granted teachers unrestricted access to the Internet, Mrs. Perry said that all of the teachers had been "updating all of their old transparencies (images) with bright, crisp and really colorful pictures from historical databases online." Mr. McHugh weighed in on the "flexibility" that he now enjoys as a result of having open access to the Web. He exclaimed, "When I started teaching, you had to find the image and print it out on an overhead (transparency). You weren't going to do that five minutes before the period. Now you can Google things."

Having an instantaneous access to the Internet had led to changes in the classroom. Unrestricting teachers' access to the Internet has allowed Mr. McHugh to follow students" interests. He stated, "If kids have a random question, we can Google it. We Google things all the time. I'm much more apt to go on a random web quest with my students than before." For example, during a lesson on China and the Opium Wars, he stated that he used the Internet to answer students' questions about opium. With unfettered access to the Internet, he said that he was able to find a relevant video on drug use to show his class the next day.

We used a video produced by a sheriff's department back in the Mid-West where you see the mug shots of people on their first arrest and two years later to see how meth use was destroying them. I tell the kids that meth is not the same as opium, but in terms of why the Chinese government would be so upset that their population was addicted to opium it was just like how this drug has been a problem in America. It became a teachable moment about drug use.

He explained how having dependable technology assisted his construction of this lesson. 
Because I had access to YouTube and Google, I did this the next day in class and we had a good twenty-five minute conversation that five or six years ago without access to YouTube, I could not have tracked down that video clip in twenty-four hours.

However, he discovered that not every video online was relevant and engaging to high school students. After showing a fifty-minute documentary on Joseph Stalin, students complained that he was boring. Mr. McHugh was shocked by their reaction.

I was getting worried about how could Joseph Stalin be boring. I mean this tyrant, this monster who did these crazy things and, yet, interesting, almost like Nostradamus. You can't turn away. But the kids were like, 'Joseph Stalin's boring.'

Responding to these complaints, Mr. McHugh now uses videos to quickly illustrate historical information. He stated, "We need to get away from these big documentaries and YouTube has opened up the ability that I can do a video clip... to illustrate what kids were seeing in the PowerPoint."

The teachers also used the Internet to post information to students. For the past several years, Mrs. Perry and Mr. Bartolo used websites like schoolloop.com, blogger.com and sites.google.com to provide their students with course material online. Mr. Bartolo published almost every assignment, presentation and study guide from his Economics and US History courses. He explained that he employed multiple strategies to ensure that students were exposed to the "main components of the lesson... twice." To accomplish this goal, he presented the material through "different mediums, in a different way of instruction so they (the students) can understand it. If they don't eat it up during my lecture, they might eat it up online." 
Mrs. Perry also provided her students with course materials on Blogger. Students had access to daily agendas, due dates and some assignments through links to Google Docs. Although her blog was available to all of her students, Mrs. Perry reflected a bias in favor of AP students over CP students in the amount of online access they have to course materials. She shared,

I do have some Google Doc links on the school website, but that's mainly for my AP students. Students sometimes ask you if you can put the lectures online and I don't like to do it because then you have people sleeping in class and telling you, 'I'll just do it at home.' I don't really want that. I can see if my AP students ask me at the end of a unit, 'Can you email me this set of slides or the lecture?' I do. I do for anyone else who wants them too.

Despite having the goal to "provide notice to students so everyone knows what they need to know," she provided CP students with limited access to class materials online.

Opportunities for Students to Use Technology in the Classroom

The social science teachers at Lincoln High School provided students with opportunities to use computers during class. Mr. McHugh and Mr. Bartolo took their students to the computer lab to complete different technology-based assignments. Every month, Mr. McHugh had his students type up a research paper or essay in the computer lab. Prior to entering the lab, students analyzed topics and construct their arguments so they could focus solely on typing when in the lab. He stated, "When I first started teaching, students on the whole were better at typing than now... because students use keyboards less than they did ten years ago." By providing them with time to improve 
their typing skills, he planned to get his students "comfortable with the formal technology you would need for college and career."

In the past year, Mr. Bartolo reported taking his students to the computer labs less often due to their limited availability. However, he managed to take them a few times during each semester to complete web quests and play interactive learning games. While "the majority of his notes came from PowerPoint," Mr. Bartolo sometimes supplemented notes for web quests. For instance, he assigned his students a web quest of the Federal Reserve's website because he believed it to be a "good resource for the high school level in terms of the way it's mapped out and the way it explains how the Fed operates and what the Fed does."

Mr. Bartolo also coupled primary source readings on the Stock Market with a free online market simulation game, called Marketwatch. For four weeks, students bought and sold stocks and managed their portfolios as they learned about investing. He stated that the game was an effective teaching tool, as well as being popular with his students. He recalled,

There are some kids with well over 100 trades in the month that we play. So they're on there way more often than the once a week we go to the lab. If you're making over 100 trades, you're on there everyday.

Unfortunately, Mr. Bartolo could not reserve the lab as much as he did in previous years. During the current school year, he had to scale back the number of web quests and supplemented these activities with "questions from readings and informational readings about what they policies and goals are." 
Since the computer labs on campus were often booked, Mrs. Perry allowed students to use the three student computers in her classroom. She stated,

If the kids are doing a poster on something or researching something and writing a paragraph about something, I can just let them use computers here. I don't have to go and get lab time. I can give them five minutes to find what they want and print it out.

She explained that in a short period of time students could obtain "information or visuals that they find after doing a quick Google or Wikipedia search that has to do with topics like the Montgomery Bus Boycott or the Greensborough Sit-Ins." However, limiting students' time on the computers had resulted in some students obtaining inaccurate information. For example, she recalled,

Somebody had Malcolm X, but the picture of Malcolm X was actually Denzel Washington as Malcolm X. Of course he did look like him, it was a good rendering of him in the movie, but I did a double take and it was Denzel Washington. They just searched Malcolm X and what they got was the movie.

Due to the limited computer access in the computer labs, all three of the teachers allowed students to use their smartphones to conduct Internet research in class. Mrs. Perry wanted "student to look up facts," but admitted, "it can be a little dangerous because once they're on, they can do anything." Mrs. Perry had some students who were "socially addicted" to their phones and other who play "cat and mouse games" in order to use their phones in class. The teachers found managing students' smartphone usage challenging when every student brought one to class. Mr. Bartolo explained,

The school has a pretty diverse population in terms of high SES kids and kids from the lower SES ladder. When I look around, it really doesn't matter. It's not even a status deal anymore... all the kids have smartphones. 
He allowed students to use their smartphones for research in class, but stated, "When we're doing something else, it's expected to be put away." Mr. Bartolo had clear expectations about phone usage and tried to ensure that students were only using it for academic research.

Although students could use their smartphones in these social science classrooms, Mrs. Perry worried that students were not selecting accurate information. She stated that students were "not too discriminating about information" they get online. However, McHugh encouraged students to use their smartphones to quickly find answers online. He argued,

I'm a fan of Wikipedia. I tell my kids you can't use Wikipedia to write a formal research paper, but if you just want to know something, nine times out of ten, it's going to know more than you and it's going to be accurate. A lot of teachers will tell the kids don't use it in your paper. It's not valid. But who is going to go and deface the French Revolution Wikipedia page?

\section{Social Science Teachers' Use of Technology to Prepare for Common Core}

The social science teachers at Lincoln High School were preparing to use technology differently for CCSS. Mrs. Perry acknowledged that the department has been "very coverage driven" under NCLB and complained, "If you try to cover everything in the standards, you're just racing through everything." She served on the school's Literacy Committee and stated, "We've got literacy standards, but no content standards yet. We have to know what the balance is." She found examples of Common Core lessons on PBS.org. She participated in a PBS online training on the West, which involved students' analyzing the Railway and Homestead Acts online. She explained, 
"There was a lot of great visual stuff about settlers and native people. You start out at the core of it with your documents and then you build around that." With these examples, she surmised that instead of lecturing on specific events that depict Westward Expansion,

The unit is about comparing these two primary source documents and asking a bunch of questions on how the two of them interlock, what were the motivations of the writers and so on. The information about Expansion will come out of that.

After receiving this training, she reported going back through her PowerPoints and selecting images and primary sources that she can juxtapose for new Common Core lessons.

In the upcoming year, all of the teachers at Lincoln High School expressed the need to prepare new lessons that meet CCSS. Mr. McHugh had worked with the administration to include collaboration time in the school day for teachers to construct these lessons. He conveyed his hope that spending time discussing what primary source documents other teachers were going to use might act as "the launchpad to seeing things in a new way." One such lesson he wanted to share with his colleagues was one where his students read Jamaica Kincaid's A Small Place. He used short video clips online to help contextualize the setting and illustrate concepts about post colonialism in the Caribbean for his students.

The teachers stated that the CCSS necessitated a change in the way historical information was presented in class. As Mrs. Perry stated, "If you're going to compare three speeches now, one by Kennedy, Castro and Khrushchev... you're really putting the brakes on the pace of coverage." Mr. Bartolo understood this and explained, "If you 
spend more time on that (analyzing primary source documents), you spend less time doing PowerPoint and less time introducing specifics about historical events." With the change in standards, Mr. Bartolo acknowledged he may have to limit the amount of thematic PowerPoint presentations he does. Mrs. Perry understood that the transition would be hard for teachers because they are going to "feel a sense of loss because you're going to have a sense of what's not being covered. Because we like history, we're going to be sad about it." However, this change may be short lived. Mr. Bartolo postulated, "Every five to ten years, there's something new. It was content then, now it's going to this core thing. In ten years, it'll be content again." If his prediction comes true, social science teachers at Lincoln High School would once again change how they use technology to meet state standards.

\section{Findings from the High SES School}

\section{Access to Technology in the High SES School}

The social science teachers reported having access to hardware, software and Internet connectivity. All of the teachers had laptops and LCD projector that were purchased for them by the parent club and the social science department, respectively. The school claimed to have a 4:1 student to computer ratio. None of the teachers reported having student computers in their classrooms, but they stated the school had one computer lab and four mobile computer carts that teachers could check out. Two of the carts held two complete class sets of netbooks that provided classrooms with 1:1 access. The other two carts held twenty iPads, which meant two students had to share one tablet. 
Mrs. Hsu and Mrs. Karishma reported using both the computer lab and netbooks on the mobile carts. Mrs. Hsu said, “Our department has a set of notebooks. They're a little slow sometimes, but they're ok. They're just better for getting on the Internet and looking stuff up. You can't do any graphics on them." Mrs. Karishma added that the computers in the library and on the mobile carts occasionally crashed, but found ways to work around the problem.

None of the teachers reported using the tablets. Mrs. Hsu explained, "They don't have a keyboard or software programs like Word." When she told her students about the tablets, she stated that they had a similar reaction.

They got excited when I told them that we had iPads at the school and we can check them out. They were like, 'Cool.' Then thirty seconds later, they said, 'What are we going to use it for? Take pictures of ourselves?'

She explained that the students did not want to use the tablets unless it would make completing classwork "easier."

Mrs. Hsu also considered purchasing an interactive whiteboard, but "didn't want to create a whole program for that." Furthermore, she stated that she would not receive any support creating new curriculum for the interactive whiteboard. She stated, "We just got a tech guy on campus. He can help fixing our computers when they crash or when our printers don't work, but he's not going to help us build curriculum."

All of the teachers had access to the Internet via Ethernet and Wi-Fi. The teachers mentioned having problems accessing the Internet wirelessly. Mr. Beckham depicted the situation the most clearly. He explained, "The Internet goes down way too often. I'll go 
to take roll and there's no Internet. It'll go down and then come back up." He also expressed problems streaming videos in class.

It used to be that I'd go to show this video and the Internet's not working or it's flagged or it stops halfway through the video. They keep saying let's use technology, but at least in this school, it's not reliable enough so you figure out ways around it.

Mr. Beckham figured out a way around this hurdle and used KeepVid (keepvid.com) to download copies of online videos so that he can show them in class without complications.

Despite being a high-income school, they had a poor Wi-Fi connection. Mrs. Karishma provided some insight into why the district was reluctant to spend more money on the school's Wi-Fi. She explained that the school had a very active and philanthropic parent club. Many of the parents donated substantial sums of money that helped the school purchase everything from necessary office supplies to a second iPad mobile cart. Since the school received donations directly from the parent club, the district limited the amount of funds they gave to the school. Mrs. Hsu noted,

It's funny because it's good we have all this support from parents, but it's bad because that the district just assumes the school will take care of it (their Wi-Fi problem). The teacher's union is always getting on us because every time we have the parents buy us something it gives the district the reason to say, 'Well, I guess you don't need that money then.'

Without consistent funding from the district, the school relies on parent donations to fix internal technology problems. According to Mrs. Karishma, the parent club was responsible for providing the social science teachers with laptops, LCD projectors and a part-time technology support person at the school. 


\section{Social Science Teachers' Technological Uses in the High SES School}

All of the teachers used technology in their classrooms on a daily basis. While all of them had Microsoft Office on their computers, Mr. Beckham was the only one who did not use PowerPoint in his class. He stated, "I'll find a video, a picture or an article online about economics and then teach it." Mrs. Hsu and Mrs. Karishma used PowerPoint for lecturing and displaying other information like visuals, videos and primary source documents. Mrs. Hsu stated that her goal was to begin with "concepts that I want to teach them (students) and whatever I'm using is just a tool." She stressed that she used technology only as a means to an end. For example, Mrs. Hsu explained,

In Government, if I'm going to teach the Executive Branch, if I wanted to do it in a PowerPoint, I can do it through a PowerPoint. If I want to do it through a reading, then I do it through a reading. Technology is just a tool.

Mrs. Karishma used her projector to display lectures, notes, images and digital media to her class. Although she admitted her technology use can be "teacher-centered," she depicted her pedagogy as "a planned series of lessons that are centered on what students need to learn.” Within these lessons, she made pedagogical changes that now include the use of podcasts, digital images and streaming videos. She explained, "You have to know your audience and change accordingly." For instance, she stated that she used YouTube to show a music video on the French Revolution, which was a parody of a popular song by Lady Gaga. She explained that the video was used as a warm-up to her lesson on the French Revolution to initiate a class discussion on the parody and the 
content material. She viewed the use of such technologies as helping to "enrich (her) lessons" and appeal to her students' interests.

Having access to information online also impacted Mr. Beckham's pedagogy. His entire curriculum came from the Internet and he did not use textbooks anymore. He expressed how he could do more with technology than he could with the textbook. Mr. Beckham stated, "I don't know how I can teach without the Internet, a computer and a projector. Technology allows me to engage students instead of me just talking or having them read out of a textbook." Instead of being satisfied with teaching from the textbook, Mr. Beckham surfs the web for captivating material that will increase student interest in the academic concepts. He said,

I try to hit them from all angles. Here's a video, here's a picture, here's a graph, here's the story. The whole thing is trying to get them interested in the subject. I'm always looking for things that kids will like and be interested in and then use that to relate to core concepts.

Mrs. Hsu also expressed how using the Internet had benefitted her. She stated, If I'm putting a lecture together and don't know the information for something, I just look it up on the Internet. I don't access this (her library of books) at all. I knew teachers in the past who pulled books out and looked stuff up. People do it, but it just takes so much more time. Now I just Google it.

She found Google so efficient that she often looks up things in the middle of

class. For instance, Mrs. Hsu shared,

Just the other day we were discussing a primary source and I said, 'Who is the author? Actually, I don't know the author for this one.' They had a name there (on the document) and I said, 'Someone Google it.' The students all pulled out their phones and Googled the name. It was good because the conversation didn't stop just because we didn't know the information. We could just look it up right away and continue talking. 
Mrs. Hsu discussed another benefit of being able to conduct online searches in the middle of lessons. She said,

It's a good lesson for them that you don't have to know all the information. It's history and it's constantly growing. There is no finite amount of information that you're learning. You're not going to know everything, you just need to know how to find the information when you need it.

At a conference she attended, another teacher shared her sentiments. She recalled, "This teacher said, 'If you only use your teacher as a source of information you will be limited by what they know.' I thought that was so true." After hearing this, she reminded her students to look beyond her as the sole source of information and use technology to find other sources of evidence to expand their knowledge.

Finding and sharing interesting information with students was a core component of Mr. Beckham's curriculum. He reported using Google and YouTube daily to show visuals and stories that exemplify the content material.

It's incredible what you can do (with technology). We'll be talking about something and we can Google a picture and put it up. Now it's not even that. You can YouTube something you're talking about and show a story about it. I totally rely on that everyday.

He explained that being able to bring these pictures and stories into class has changed the way he presents material. He said, "I used to have a recording of JFK's inauguration speech, my favorite speech, and I put a picture up there with the speech. Then you go to YouTube and they have the real recording."

Prior to having open access to the Internet, Mr. Beckham recalled that the district blocked numerous websites. He said, 
One of the technology guys in our district made a unilateral decision not to allow teachers to use YouTube and a gazillion other sites because he thought we would badly influence our students. In a way, it made the whole Internet useless.

Blocking much of the Internet proved to be ineffective. Several years ago in Mr.

Beckham's Government class, his students read an online article about the scandal

surrounding the resignation of the former Governor of New York, Eliot Spitzer, for using tax dollars to pay for prostitutes. He recalled,

I teach Government and we were talking about it. I said it wasn't the fact that he was going to call girls that people were upset about, it was because he was using taxpayer money to pay them. In the article, they mentioned the service that he used. Students said, 'Google it. Google the service.' I said there's not going to be anything because we can't even get YouTube. So I Googled it in front of the whole class and it was there. The website for this call girl service was there with all their names and prices. They had pictures, of course. Nothing like X-rated pictures, but they weren't G-rated either. It was funny because I couldn't get on YouTube and show Kennedy's speech, but I can see Eliot Spitzer's prostitute organization and the prices of all these hookers.

To improve Internet access at the school, Mr. Beckham pressed the school board for unfettered Internet access. Due to those efforts, all of the teachers were able to freely use the Internet during class.

I took on this task for over two years. Going to the school board and speaking out and getting other teachers and kids going up there and saying, 'We want this. Stop blocking it. Just trust us.' Eventually, long story short, they approved it.

\section{Facilitating Student Learning Opportunities through Technology}

Two of the social science teachers at the high SES school used technology for professional enrichment activities. Mrs. Karishma stated that she frequently searches college websites for professional development and has attended numerous trainings at University of California, Berkeley, Stanford University, University of the Pacific and 
even at the County Office of Education. She explained, "It is important to be in professional development to enrich your own knowledge. That knowledge can then be brought back to the classroom to benefit your students." She also used the Internet to contact and book educators and community leaders to come to her classroom and speak to her students. For example, she invited a professor from Stanford to speak to her Ethnic Studies class about his experience during the Civil Rights Movement and the challenges he faced as an African-American male in America.

Mrs. Karishma also used the Internet to find opportunities for students' learning outside of the classroom. Several years ago, she participated in a Fulbright Teacher Seminar where she studied and visited the German school system. After this experience, she helped create a cultural exchange program for high school students in both countries. Utilizing the World Wide Web, Mrs. Karishma orchestrated not only student trips between the two countries, but also students' online communication about the similarities and differences among their school communities.

Mrs. Karishma was not the only teacher who uses the Internet to organize unique learning experiences for students. Mr. Beckham used the Internet to learn about and invite successful technology and business leaders, educators and politicians to share inspirational stories with his students. For example, in an online newspaper article, he discovered the story behind the creation of Piazza (Piazza.com). Mr. Beckham explained that Piazza was a website that allows college students to collaborate and offer help to other students online. He was “impressed with her (Piazza's founder) ingenuity and 
thought she would be a great speaker for my students." He invited her to give a guest lecture in his class and exclaimed that "she spoke to my class about economics and she was as great in person as I thought."

\section{Opportunities for Students to Use Presentation Software in the Classroom}

Mrs. Hsu and Mrs. Karishma had students use technology to present material. Mrs. Hsu frequently made her students responsible for presenting material in class. She stated, 'I'll say, 'Make something creative.' You can do a poster, a PowerPoint, a skit, a video. You can do whatever you want. They usually come back with something cool." She added,

You force them to (present) because some of them are really so shy. They need practice. It's easier to get up in a group than it is by yourself. I tell the kids all the time that you can be the smartest person in the room, but if you can't say anything, no one will know.

Students in Mrs. Karishma’s class were also assigned technology-based projects. Although she proclaimed herself as not being "technologically savvy," she provided her students with opportunities to use technologies to create two videos and two presentations throughout the year. In the beginning of the year, students created a three-minute video on iMovie or Movie Maker that portrayed a part of their life. She encouraged students to share any skills, talents, interests or passions with their peers. Students also composed and typed an essay entitled "Who am I" that provided more details about this part of students' lives. The second video project was a short documentary. To graduate, all students must complete forty hours of community service. Mrs. Karishma helped them to "showcase" a portion of their community service through a video documentary. Students 
worked on these projects in the computer lab and at home and displayed their final products in class.

Twice a year, Mrs. Karishma had students construct a presentation on different cultures using PowerPoint and Prezi. Students spent a few days either using the netbooks or the computers in the lab to conduct Internet research, gather visuals and edit their presentations. For their first presentation, students shared information about their culture with their peers. For their second presentation, students researched a culture they were unfamiliar with and then shared their findings. She expressed that the projects enabled students to "link the commonalities between different cultures and cultivate mutual respect and understanding."

\section{Opportunities for Students to Use the Internet in the Classroom}

Teachers' ability to freely access the Internet created opportunities for students to use the Internet in class. Students were allowed to access the Internet with their smartphones in all three teachers' classes. Mr. Beckham questioned why educators would restrict students' smartphone usage in class. "The fact that we would block it from them and they already have it is ridiculous." Mrs. Hsu encouraged students to use their smartphones for academic tasks throughout class. She depicted her students' comfort using their smartphones in her class.

They read the documents on their phones, they look at assignments on their phones, they check their grades with their phones, they take pictures of what I have on the board with their phones. They don't even take notes anymore. They just take a picture of it. 
In addition to allowing students to use their smartphones in class, Mr. Beckham had begun planning lessons that utilized the apps on students' smartphones.

There's a phone app that does blind surveys. There are kids who don't want to say anything in class for whatever reason. You can ask the kids questions about how many would vote Republican or Democrat and on the computer a number will come up. I don't have to single them out.

Through this app, Mr. Beckham stated that he could bring forth information from students that they may not have otherwise been willing to share.

Eliciting students' thoughts through discussion was another goal of Mr.

Beckham's. To facilitate more student discussion, he had the students use Piazza. While the site facilitated collaboration among students, he used it for "online discussions about topics we talked about in class. Like 'Should we arm teachers? Give me your opinion."' He reported that students liked the website and the ability to "argue" controversial issues.

Mrs. Hsu integrated the social networking website Facebook (Facebook.com) into her class. Though she already used her school loop page to post course materials, she wanted to use Facebook because her students preferred it. She said, "It doesn't make sense for me to use something that they're not using." Since creating the AP World History page, she reported students using it to view primary source documents, class assignments, test review questions, as well as sharing notes and comments for other classes. Mrs. Hsu also wanted students to "learn how to use technology appropriately." She explained,

For me, it's really important that students learn appropriate behavior before they go out into the real world and college. They don't realize that everybody can see what you're writing. Your bosses will look your Facebook page up. 
Although these teachers are fostering students' technology use in class, they were going against district technology policies that restricted such usage. Mrs. Hsu criticized these restrictive technology policies.

To me, it's like a losing battle because it's like we're forcing the schools to stay in the Dark Ages when everybody else is ahead. You're either going to get left behind or you have to stay with the trend. That's the reality. That's the future, so you can't just put your head in the sand and pretend like it's not happening.

\section{Emergent Themes from the Data}

\section{Constructing Workarounds for Technological Challenges}

Across SES, all of the social science teachers had access to similar technologies. At each school, the teachers had a laptop, LCD projector, presentation software and Internet access. The majority of teachers did not have additional computers in their classroom for student use. The teachers also had access to computers either in labs or mobile carts. However, across SES, teachers reported that the computers were slow and occasionally crashed.

Two notable differences arose regarding how teachers accessed the technologies available to them at their school sites. First, teachers in the school that served predominantly low SES students did not provide them with access to computers in the library or from the mobile carts. These teachers mainly used their technologies to show students PowerPoint presentations, digital images and videos. Ms. Giannino explained that many teachers did not want to bring additional technology into the classroom for fear that it would be stolen. She stated that students had stolen laptops, projectors and 
smartphones from teachers and other students. Though she wanted to use her two tablets in the classroom, she did not because she was afraid they would be stolen. Mrs. Cook also revealed that students have vandalized Ethernet ports in her classroom making them inoperable. These problems were reported only by teachers at the school that served mainly low SES students.

Mrs. Cook stated that the computer lab was not a viable option for her students because only $1 / 3$ of them were fully functional. She had a similarly unsuccessful experience using the laptops from the mobile carts. She stated that $60 \%$ of the class was devoted to helping students prepare their laptops for use, which left little productive time for students to complete their assignments. After these experiences, she stated that she did not try to use the computers or laptops again. Instead, she opted to have students use the three computers in her classroom when needed.

Teachers at the schools that served mainly middle and high SES students reported similar problems with the computers in the labs and mobile carts. Two teachers at each school continued to use the computers even though they were outdated, slow and sometimes inoperable. Despite the frustrations expressed by teachers at both schools, they reported finding ways to work around the technology problems. Since the computers acted up frequently, the teachers had students save their work on USB drives and work in partners when computers crashed.

In the school with mainly high SES students, Mrs. Karishma also complained that the computers in the library had firewalls and filters that limited online access. She 
explained that the security measures blocked her students from accessing online sites to communicate with students in other schools as part of her UN project. She then turned to the netbooks and, although she noted they were slow and sometimes crashed, students were able to access the necessary online sites to complete the assignment. Mrs. Karishma and Mrs. Hsu also allowed students to use their smartphones when computer problems arose. Mrs. Hsu stated that the technologies were "problematic," but with "lots of netbooks combined with smartphones, we somehow get what we need to get done." Despite expressing these frustrations, the teachers of middle and high SES students reported finding ways to work around their respective technology problems.

Though the schools with middle and high SES students had mobile tablet carts, neither group of teachers used them. In the school that served high SES students, Mrs. Hsu choose to use the older netbooks because the tablets lacked a keyboard and word processing software, making it difficult for students to type responses digitally. Meanwhile, all of the teachers in the school that served middle SES students expressed a desire to use the tablets. Mrs. Perry stated that the tablets would allow students to analyze digital images in small groups, but could not access them until the pilot program concluded at the end of the 2013/14 school year.

Next, the data showed that the social science teachers in schools that served mainly low and middle SES students had more reliable Internet networks than teachers in the school with high SES students. While all three of the schools had Ethernet access, only schools serving middle and high SES students had wireless access. In the school 
with mainly low SES students, Mrs. Cook was not bothered by the lack of Wi-Fi and was complacent with the "dependable" Ethernet connection for the student computers in her classroom.

In the school that served predominantly middle SES students, the teachers expressed how using the Internet allowed them to access a variety of digital documents, images and videos. While the teachers expressed satisfaction accessing these sources online, Mr. Bartolo was the only teacher who had problems accessing online videos. He said, "Sometimes online videos can be an issue. Certain things just won't play. I can run YouTube videos just fine, but some videos off other websites just don't work." He explained that much of the problem had to deal with not being able to download new versions of media players. "That's always a problem because they ask you to download this version of Adobe or whatever to run it and a lot of times it's restricted. You need an admin person to upload new stuff on your computer." However, he figured out a way to bypass this obstacle. He boasted, "I've become pretty cool with the tech guy here and I can grab him and ask him if he can come into my class and check this or that out." Mr. Bartolo was not the only person to receive this support. Mr. McHugh clarified that the school employs two computer technicians to solve all kinds of "computer crises" that arise for teachers.

In the school that served mainly high SES students, the Wi-Fi and Ethernet connections were not as stable. Mr. Beckham and Mrs. Karishma both testified to the school's network being "unpredictable." Mr. Beckham stated that the school "needs 
better bandwidth" so as to not impede teachers' and students' Internet access. However, Mrs. Karishma pointed out that it was unlikely to happen unless the parent club paid for it. While she said the district could pay for high-speed Wi-Fi, Mrs. Hsu predicted that district leaders would wait to see if the parent club offered financial assistance before they committed to fixing the issue. In the meantime, teachers worked around the problem and saved many of their Internet resources on USB drives.

\section{Technology Use for Test Preparation}

Under NCLB, the social science teachers were required to cover specific state content standards. Many of the teachers in this study brought up the difficulty of covering such a wide body of historical information. These teachers used technologies differently across SES to meet these goals.

Across the different SES communities, the majority of social science teachers used PowerPoint to present lecture notes on historical subject matter. In the school that educated mainly low SES students, the teachers heavily relied upon lectures notes to convey much of the material to their students. Mr. Costa explained, "It's a mad dash to the point where we take state tests" and to cover all of the material he admitted that students "sometimes just need notes." No one expressed the pressure more than Ms. Giannino. While she used PowerPoint lectures in her CP classes, no technology was used in her AP classes. She stated, "I lecture all the time, which is why my voice is scratchy. I just got done with one (and it lasted) for the entire period." She explained that technology did not help her cover almost 1,400 pages of information in the AP textbook. 
Though the teachers in the school that served mostly middle SES students used PowerPoint to lecture, they also covered the content standards through numerous visuals. The teachers reported using digital images, photographs, artwork, maps and charts in their presentations. Having a plethora of digital images online, Mr. McHugh said that he "likes to spiral through images in class on my projector." Mrs. Perry explained that presenting digital primary and secondary source images gave students time to analyze and discuss the content material than when she lectures.

While the teachers in the school that served predominantly high SES students also used lecture notes and digital images in their presentations, they reported one notable difference. All three of the social science teachers incorporated primary source readings into the ways in which they taught the content standards. Mrs. Hsu stated, "In AP World History, we do a lot of primary sources. I'll get stuff online that people wrote... and excerpts from different documents." For Mr. Beckham's Government and Economics classes, he used current and historical primary sources because "for social science... there's a ton of stuff." For example, he explained, "there's nothing about Obama in our textbook. I go online and find plenty of primary sources on him and his administration." In addition to having students read and analyze these sources, Mrs. Karishma also reported that she used digital images to support concepts and ideas from these readings and excerpts.

With Common Core taking effect in the $2014 / 15$ school year, more primary sources must be covered in social science classrooms. Each school site had one teacher 
who used technology to find professional development opportunities to meet the requirement. However, the school that served predominantly high SES students had the greatest number of teachers attend such professional trainings for CCSS.

From the school that served mainly low SES students, Ms. Giannino said that she had took part in a PBS online training that demonstrated how to have students analyze digital articles and videos and post their responses via Twitter. Despite the training, she did not end up integrating this technological activity into her curriculum because she found managing thirty-four students' smartphone usage "too difficult.".

From the school that served mostly middle SES students, Mrs. Perry reported using the Internet to locate examples of Common Core lessons in history. She stated that she recently "took an online class on the PBS website for the series The West," and learned that her lessons will have to be "recast with (primary source) documents and built out from there."

From the school that served predominantly high SES students, Mrs. Karishma used the Internet to frequently locate different professional development opportunities. She stated the most recent professional training was on using technology to teach the Common Core through primary sources. She sent out the information to her colleagues in the social science department and reported that a total of five teachers attended.

\section{Teaching Students to Use Technology for Life after High School}

All of the social science teachers in the study were cognizant that they were helping to prepare students for life after they graduate high school. This study found 
differences in the goals teachers espoused across SES. In the school that contained mainly low SES students, Mr. Costa stated that he was teaching the "future leaders of the world." He explained that he had difficulty trying to convince his students that they could use social science skills to obtain professional jobs.

I am not teaching you history this year so you can go out from high school and be a food picker... or a McDonald's worker. I don't want to offend anybody who works at McDonald's... or is a food picker. They are very hard jobs and they need to be done. But at this school, we're not teaching you so that you can go out and get a manual labor job. We're teaching you to be a higher educated person. It takes the kids off their guard because nobody's ever really said it to them. They need to hear it though. They need to hear that I want them to be a doctor, a lawyer, a nurse, a computer tech. I want them to be something using their brain more than just the same task over and over on an assembly line.

Ms. Giannino stated that her goal was to get students ready for college and career.

While she used presentation software to have students copy down lecture notes, Ms.

Giannino gave students one opportunity to construct their own PowerPoint presentation.

By doing this presentation, she stated that students practiced their communication skills.

For example, she argued that it was important for low SES students to learn how "to not use slang and... code switch" in order to prevent "the professor from making fun of you" in college. She also encouraged her students not to swear at other people. She said swearing at work "could end your career right there." She warned, "If you say m-f to your boss, you're not going to keep your job."

Mr. Ackerman also wanted his students to go to college. When asked if students enjoyed his PowerPoint lectures and answering the questions, he replied, "They see the question and just do it. They don't like it, but I don't accept whining." He proclaimed, 
"We need to prepare these kids for college and they won't be prepared unless I teach them how to think critically and how to be responsible for what they have learned." Although he acknowledged that his job was to prepare students for college, he complained that low SES students did not work hard enough.

In the school that contained mostly middle SES students, the teachers expressed their support of students' attending college, as well as any other path students may choose to take after high school. To prepare students for college, all of the teachers allowed students to use their smartphones to conduct Internet research relating to specific topics. They also provided students time to analyze digital images and deconstruct them in small groups. Mr. McHugh also had students type essays on the computer. His technology lessons were designed to get students "comfortable with the formal technology you would need for college and career." He stated, "They can do the research, they write eloquently, but it's the typing." He frequently took students to the computer lab to develop their typing skills so that they could efficiently type papers in college and their careers.

In the school that contained predominantly high SES students, the social science teachers expressed the goal to provide students with technological learning experiences that would not only prepare them for college, but as leaders, innovators and CEOs. Mrs. Hsu separated the types of students at the school into two groups, social and shy. She said she used technology to have students discuss primary sources and present content material in front of the class. She said that assigning these activities allowed all of her 
students to practice their social skills through discussions and presentations. Mr. Beckham and Mrs. Hsu also provided students with opportunities to develop these skills online. These two teachers used Facebook and Piazza to facilitate student discussion, debate and the sharing of ideas and concepts. Mr. Beckham explained that by providing students with these social and technological learning experiences, they would be ready to use these skills in college and career.

In addition to discussing and presenting material digitally, Mr. Beckham and Mrs. Karishma researched and communicated online with professors, politicians and business leaders to get them to do guest lectures at their school. Mr. Beckham explained, "I don't want my students to be great employees, I want them to be the ones that start the companies and come up with their own ideas." Mrs. Karishma provided her World History students with the opportunity to become leaders among their peers. In her UN Project, students communicated and collaborated online with students from other schools in California to solve global problems.

Engaging Students through Technology-rich Learning Opportunities

Across SES, social science teachers employed different technological practices to engage students in the content material. The teachers in the school that served mainly low SES students claimed to engage students in their PowerPoint presentations through the lecture notes, reflective questions, quotes from historical figures, pictures and videos to support that material. However, at least one of the teachers realized that using 
PowerPoint was not always an effective strategy for engaging students. Mr. Ackerman

shared a conversation he had with a student who was struggling in his class.

I had talked to a girl about Malcolm X. She had read and done homework about Malcolm X. I talked about him and showed a video clip of him talking about his views. After class, my student asked, 'How can I do better?' I said, 'Well, tell me about Malcolm X.' She just froze. I said, 'Where were you when I was talking about him?' She said, 'I was in my own little world.' She zoned out. She had notes about him. She knew there was a test about him. She wrote about him and turned in homework and she had no recollection. That's just bizarre and that's frightening. But that's not uncommon either.

The other teachers in this low SES setting provided students with one opportunity to use PowerPoint. While Ms. Giannino and Mrs. Cook assigned students presentation topics, Mr. Costa allowed student to choose their own topics. According to Mr. Costa, students were more engaged in using technology to construct their presentation when they researched subjects of interest to them, instead of being assigned topics. He explained, "Originally, I tried to make it history bound. But then I made a little turn and had them do subject that they were interested in, like the history of texting, communication, music, tennis shoes." He recalled one particular project where a student produced a music video on K-Pop (Korean pop music). He said, "She was motivated because it was something she was interested in and she did an amazing job because of it." In the school that mostly served middle SES students, students were provided with more opportunities to engage social science content material through technology. While all of the teachers reported using PowerPoint to lecture, Mrs. Perry and Mr. McHugh used it more to display and analyze digital sources, such as images, artwork, political cartoons, maps and charts. Mrs. Perry explained that the goal was to "give the 
kids the chance to look closely and talk about what they see." Mr. Bartolo agreed that student-talk time was important in his class. He created thematic PowerPoints to have his students take a greater role in presenting the material by portraying characters on the slides. He explained that Economics can be "kind of dry" and adding themes into his PowerPoints helped keep students "awake."

The teachers of middle SES students also utilized Internet websites to enrich their lessons. Mr. Bartolo reported using the online game Marketwatch to enrich his lesson on investing. Mr. McHugh explained that online games were popular on campus. He said, "Some of our students already bring their own laptops to class. They like to do computer gaming and will hook their daisy chain of wires up at lunch and game.” Mr. Bartolo reported that Marketwatch was so popular with his students that they downloaded the app on their smartphones and were trading daily. In some extreme cases, he stated that some of his students even "created their own investing games on the website."

Mr. McHugh added that he went on web quests with his students in class. He stated that he could quickly access articles, pictures or videos on the Internet to create mini lessons based on students' questions that arose in class. He contended that students were engaged in classroom discussions when he used online sources to delve deeper into their questions and interests.

Lastly, the teachers in this middle SES setting reported an increase in smartphone usage by students. Mr. Bartolo and Mrs. Perry expressed that competing with smartphones for students" attention can be "a battle." Instead of fighting these battles, the 
teachers decided to leverage students' smartphone use to engage them in historical research. They explained that students could use their smartphones like computers to conduct Internet research for projects, essays, propaganda posters, comic books and other history projects.

The social science teachers in the school that predominantly served high SES students supported using technologies to engage students in the content material. While none of the social science teachers claimed to be technologically savvy, they expressed a desire to facilitate student-centered technological learning experiences in their classes. Mrs. Hsu thought that incorporating more technology would help the school emerge from "the Dark Ages" and stay current. All of the teachers agreed that accessing technology let them find digital material to enrich their curriculum. Mr. Beckham explained that technology allowed him to find and display digital articles, pictures, videos and stories to engage students in learning content matter that students would find interesting.

Mrs. Hsu and Mrs. Karishma said that students used computers, netbooks and their smartphones to analyze primary source documents and images and create presentations. Mrs. Hsu stated that students were also frequently asked to discuss and present course material. By "changing things up" and having students present with technology, Mrs. Hsu contended that students gained important social and academic skills when teaching concepts to their peers. Mrs. Karishma explained that her students leveraged technology to create a total of four presentations. She stated that the presentations enabled students to engage in academic research and technological learning 
activities where the end product would "showcase" their talents, skills and cultural heritage with their peers.

All of the teachers created digital spaces for students to engage the content material. Mr. Beckham said that his students used Piazza to discuss and debate political, economic and controversial topics. Mrs. Hsu stated that she published her course materials on Facebook because students could easily access, discuss and post additional materials when needed. Mrs. Karishma said that she had her students collaborate online with students from other schools to solve problems affecting the world today. Collectively, teachers in this high SES setting expressed the importance of giving students time to access and use the Internet for educational purposes.

\section{Conclusion}

Social science teachers from three high schools with the majority of students from low, middle and high socioeconomic backgrounds shared concerns about four aspects of using technology in their classrooms. The hardware at each school was outdated and some inoperable and improving software would not be possible without updating both. Additionally, Internet connectivity was a concern. Even with current hardware and software, not being able to connect to the Internet when needed limited teachers' and students' use of technology in the social science classroom. Finding ways to bypass these problems marked differences among the teachers. Teachers at schools serving mainly low SES students displayed less innovation for finding ways to workaround their technological limitations than were teachers for higher SES students. 
The social science teachers shared the motivation to use technology to prepare students for standardized assessments. While teachers for low SES students were found to mainly use technology for direct instruction, teachers for higher SES students used technologies to enrich students' learning. Teachers used pedagogies from each end of an engaged learning continuum to describe their use of technology. In some cases, teachers merely flashed lecture notes on a screen, which resulted in a passive form of student learning. In other cases, teachers used original course documents, artwork, videos, charts and graphs not found in the textbook. Moreover, these technology uses were more clearly understood by the goals teachers had for their students after they graduated high school. Teachers for low SES students were more likely to sacrifice student engagement for strengthening their social science skills and knowledge. Teachers for middle and high SES students employed more strategies where technology was leveraged to not only engage students in learning, but also develop the 21 st skills needed to succeed in college and their careers. 
Chapter 5: Discussion and Recommendations

Overview

This qualitative study explored the ways in which social science teachers in schools with low, middle and high SES students use technologies in their teaching. A qualitative research design was employed to answer the following research question: How do high school social science teachers use technologies across socioeconomically diverse classrooms? Social science teachers at three high schools in the San Francisco Bay Area were selected to participate in the study, from which ten teachers serving socioeconomically diverse student bodies volunteered to take part in the study. The participants answered questions regarding their use of technologies in the classroom. Although the questions were based on the literature review, they allowed for the flexibility to ask teachers follow up questions that would elicit more revealing information about how they used technology.

In this final chapter of this study, the findings are analyzed from perspectives in prior research. This chapter is divided into three sections: an interpretation of the findings, implications of the practice, policy and future research and recommendations to school leaders based on these findings.

\section{Interpretation of the Findings}

Although there was at least one computer in each classroom, and other computers and laptops in labs and on mobile carts, use of these computers was limited by the speed and reliability of schools' Ethernet and Wi-Fi. Although Parsad and Jones (2005) 
reported that all of the teachers in their study had access to the Internet through the Ethernet, in this research there was considerable disparity in the functionality of Internet connections across the three schools. While the school that served predominantly high SES students also had Wi-Fi, the greater reliability of Ethernet at the schools with mostly low and middle SES students would seem to give those students benefits over high SES students.

However, teacher leadership maintained a socioeconomic hierarchy of digital education. Even with less reliable Internet access, social science teachers at the schools with mainly middle and high SES students used technology more in their classrooms, and used these technologies to impart higher order thinking skills, than did the teachers for low SES students. When hardware, software or connectivity challenges arose, teachers of higher SES students were able to bypass problems with creative solutions. These teachers naturally did workarounds and took a constructive approach whenever they encountered problems with technology. They figured out ways to make technology work, to find and share primary sources with their students and to actively expect students to critically evaluate a variety of perspectives illustrated by those primary source documents. For teachers of low SES students, the greater reliability of Internet access was not a great asset because the teachers lacked the technological savvy and because they chose to use technology to impart basic skills and facts, rather than for meeting critical thinking goals. 
This finding also illustrates the pedagogical difference between Ethernet and WiFi connectivity for these teachers. Ethernet was used to connect teachers' computers to the Internet, while Wi-Fi gave teachers and students the ability to access the Internet anywhere in the classroom. Since teachers for low SES students restricted students' technology use inside the class, they had no need for Wi-Fi. However, the teachers for higher SES students supported a variety of ways in which students used the Internet in the classroom, including laptops, netbooks and students' smartphones.

While all of the teachers were under pressure to use technology to prepare students for standardized tests, college and careers, teachers' technological practices varied across SES. The teachers at the schools that served predominantly middle and high SES students approached the use of technology through an "embellishing" model, where teachers embellished student learning with technologies. Teachers supplemented textbook content with primary source documents and images, stories, web quests and educational games. On the other hand, teachers at the school that served mainly low SES students approached the use of technology through a "distributive" model, where they used technologies to distribute and reiterate content directly from the textbook. These findings corroborate Kennedy (2010) and Harris and Hofer (2006) who found that teachers used technology to present notes and information, visuals and videos to their students.

This exposes two digital inequities. Firstly, through these technological activities, low, middle and high SES students received opposing messages about knowledge and 
learning. By using presentation software to reiterate information from the textbook, low SES students were learning to view the textbook and their teacher as the only two credible sources of information. The teachers of middle and high SES students used a myriad of online resources to teach students how to analyze and critique accurate and inaccurate information. By having these technological learning experiences, middle and high SES students will be better equipped to navigate through the increasing amount of information in our society.

Secondly, teachers of low SES students exposed them to only one view of history, government and economics. By learning the social science subjects from a narrow viewpoint, students do not have the opportunity to explore and learn about different perspectives. Since many low SES communities in the Bay Area are compromised of people from diverse backgrounds, developing an understanding and respect of peoples' values and perspectives can provide students with valuable knowledge and skills to use when interacting with other individuals within their community. In contrast, middle and high SES students received a variety of sources and perspectives. Having the opportunity to analyze and discuss these viewpoints can be expected to help higher SES students to more effectively communicate, collaborate and potentially lead diverse groups of people with respect and understanding.

This study also confirmed findings from Doppen (2004), who noted that student engagement increased when social science teachers had students work with primary sources on a computer. In fact, this study found that teachers of higher SES students 
reported higher levels of student engagement of primary sources than Doppen (2004). However, teachers of low SES students did not incorporate primary sources into their curriculums. Since these teachers did not use such sources, they could not engage low SES students in this way, thereby widening the opportunity gap across SES.

Teachers in schools that served mainly middle and high SES students did not have students access these digital resources on tablets. However, this may not be as big of an equity concern as first thought. For example, Schleicher (2011) found that student engagement decreased after the novelty of using technology wore off. In accordance with Booth's (2008) findings, students preferred using technology that they could easily use to complete their assignments. Although none of the students in this study accessed the tablets, teachers of high SES students reported that these students were only interested in using technologies that would allow them to efficiently complete classwork, projects and presentations. This finding illustrates that it is not as important to have students use the latest technologies simply for technology's sake, rather how technologies are used matters most.

The study revealed another inequity regarding students' use of technologies to construct projects. This study found similar results to Bebell et al. (2004) and Warschauer et al. (2004) in that high SES students designed more projects with technology than low SES students. However, in contrast to Bebell et al. (2004), teachers of middle SES students did not report assigning them presentations to be completed with technology. Furthermore, teachers for high SES students provided students with more 
frequent formal and informal opportunities to present with technology. Thus, there is a technological opportunity gap among low and middle SES students who do not get to use technology to construct presentations like their higher SES peers.

This inequity will harm low and middle SES students because they will not develop a familiarity with presentation and video software. If they do not have opportunities to use these programs in school, they may not learn how to use them in their adult lives. Furthermore, low and middle SES students will not become comfortable using technology to make presentations to their peers or coworkers. They may shy away from future opportunities to present information and showcase their technological and social skills because they did not practice these skills in high school. By not developing these skills during their adolescent years, low and middle SES students may find themselves to being relegated into passive positions of receiving information instead of creating and presenting information.

\section{Implications of the Research}

Perpetuating Socioeconomic Hierarchies through Technological Learning Opportunities

This research has implications for perpetuating power inequities across socioeconomic groups of students. The findings from this study demonstrated that a digital divide exists among the technological practices of social science teachers across SES levels of students. Teachers in the school that served mainly low SES students used technology to distribute information to their students, while teachers in schools that served mostly middle and high SES students embellished student learning with 
technology. These differences in how technology was used sets up low SES students to receive basic and remedial skills, while higher SES students obtain $21^{\text {st }}$ century skills. The gap in skill attainment may well carry over to the workplace as lower-skilled individuals will be unable to compete for higher-skilled jobs. Meanwhile, middle and high SES students will have the opportunity to develop higher-level skills enabling them to compete for professional and leadership roles in their future careers.

This study demonstrates how technology, once thought to possess limitless educational potential, actually perpetuated class differences and fostered social reproduction. While teachers of low SES students wanted to students to attain careers using their brains instead of their brawn, the teachers' technological practices did not match these sentiments. Teachers used technology for direct instruction to fill gaps in students' skills and knowledge that carried over from previous grades. This monopolization of technology by the teachers resulted in low SES students having extremely limited opportunities to use technology themselves. For example, the one time during the year students were allowed to use technology to complete a project, they were not provided with access to computers at school. This practice reinforced the digital divide because students who did not have access to computers or the Internet at home may not be able to complete the project and thus may earn a lower grade in the course.

While the teachers' goal was to provide low SES students with the skills and knowledge needed to succeed in college, they omitted technology use from this equation. Limiting students' exposure and experiences with technology is a problem because it 
reinforces the gap between those who have the opportunity to access and use technologies and those that do not (Banister \& Fischer, 2010). Today, virtually every college and career employs the use of technology at some level. By restricting students' access and use of technology in school, they will not be prepared to succeed in college or a career. The students who do not attend college and obtain additional skills and knowledge from a higher institution will not be able to equitably compete for jobs with college graduates. With fewer blue-collar positions available in California (Mortenson, 2009), non-college graduates will face greater competition seeking lower-level positions. Without equitable technological learning opportunities students will struggle to succeed in college and establish themselves in a career of their choosing.

Unlike the social science teachers of low SES students, the teachers at the school that served predominantly middle SES students were not preoccupied with re-teaching basic skills and limiting students' access to technology. Participation characterized the teachers' technology use in this middle SES setting. Teachers provided students opportunities to take on roles in thematic lectures, play online economic games, conduct Internet research on computers and smartphones and analyze and discuss historical images. The teacher of middle SES students ensured that students gained familiarity and comfort using technology to accomplish tasks that would be required of them in high school, college and their future careers.

Although these technological activities were done to enrich the content material, teachers of middle SES students did not provide them with opportunities to collaborate 
with their peers to construct solutions to problems. Students were learning to use technology to locate, analyze and effectively communicate their opinions in a format that would be required in college and many white-collar careers, but not to develop the problem solving skills that leadership positions would require.

At the school that served predominantly high SES students, the social science teachers used technology for teacher and student-centered activities. While some of these technology uses were similar to technological practices of the teachers of middle SES students, there were key differences. By analyzing current and historical sources online, teachers of high SES students equipped them with a frame with which to understand and respect multiple perspectives and cultures. High SES students also received frequent opportunities to use technology in the classroom and in online communities to communicate and collaborate with peers on assignments, discussion prompts and problems to solve. By using technologies in these ways, high SES students were developing the skills they would need to enter into leadership positions in the $21^{\text {st }}$ century.

This research demonstrated how the use of technology may, in fact, exacerbate the digital divide and opportunity divide rather than help overcome it. Low SES students learned that the purpose of technology is to assist with memorization, where it can help them get "correct" answers. By conveying that message, educators reinforce the power positions of low-income parents, to do as they are directed by those that are better educated and in higher-level positions. 
Furthermore, there are unintended consequences to using technology in such disparate ways. Lower and higher SES students are reinforced for thinking that people in the same socioeconomic positions learn things differently, apply that knowledge differently and use technology differently. On the one hand, lower SES students are likely to learn to complete tasks individually, without the help of their peers and outside sources from the Internet. On the other hand, higher SES students are likely to learn to work with their peers and complete projects using collaboration, critical thinking and Internet-based resources. Thus, social science teachers' use of technologies might likely reinforce low-level positions for lower SES students rather than help to overcome differences in power relationships among higher SES students.

Developing Workarounds to Enrich Students' Learning through Technology

Social science teachers today face many challenges to not only using technology in the classroom, but also using it to meet goals. Teachers must develop curriculum around state-approved content standards and prepare students for annual standardized tests. Teachers must also provide students with the skills and knowledge that they will need to be successful in their futures. Lastly, teachers must do all this with groups of students who are more comfortable using technology than teachers sometimes are.

While all of the teachers in this study acknowledged their obligation to prepare students for standardized assessments, not all teachers were able to leverage technology to accomplish that goal. Though none of the teachers in this study described themselves as being technologically savvy, teachers of middle and high SES students were able to 
devise ways to work around technological challenges. On the other hand, teachers of low SES students were unable to move past their discomfort with technology. Developing ways to bypass technological problems enabled teachers of middle and high SES students to balance content standards with critical thinking through technology.

There are implications for low SES students if their teachers cannot workaround obstacles to using technology for teaching and learning. In agreement with Zhao (2007), the teachers in this study felt pressured to prepare students for standardized tests. There was a general feeling from the teachers that the practice of teaching to the test influenced not only their pedagogy, but also how students' viewed learning social science.

As the teachers transmitted mass amounts of information through their PowerPoints, students were learning to compartmentalize historical knowledge. Low SES students learned that historical knowledge was a set of facts. Employing this didactic use of technology preoccupies low SES students with memorizing historical truths instead of exploring, analyzing and discussing cause and effect relationships, problems and solutions and key decisions made by influential leaders. Thus, low SES students were more likely to have a limited understanding of how to participate and make educated decisions in our diverse world.

Since teachers in the school with predominantly low SES students were unable to find ways to workaround the pressures associated with standardized testing, they did not seek opportunities to enrich their curriculum through technology. This can be problematic when the current generation of students have grown up in a technology- 
saturated society and are comfortable using technology. Kennedy (2010) found that students took a greater interest in their learning when they were able to use technology in the classroom. This study found that the teachers of middle and high SES students provided them opportunities to use technology to incite interest in learning the subject matter. However, teachers of low SES students restricted their use of technology in the classroom until after the STAR test. Limiting low SES students' access and use of technologies helped to exacerbate the digital divide and detach students from their learning.

Teachers at the school with mainly low SES students were complacent using the available technologies. These teachers relied on direct instruction and restricted students' use of technology. However, teachers at the schools with mostly middle and high SES students were more motivated to use technologies in ways that would engage their students and enrich their curriculum. In congruence with Bryant's (2010) findings, teachers of middle and high SES students used technologies to provide students with more relevant learning opportunities than those teachers of low SES students. Teachers of middle and high SES students enabled their students to use technology to explore, analyze and discuss historical sources. In addition, high SES students used technology to construct presentations and collaborate online with peers. By creating solutions to their technology-based problems, the teachers were able to leverage technologies in ways that would prepare their students to succeed on standardized tests, in college and in their careers. 
Teachers in the schools with predominantly middle and high SES students demonstrated more innovation than the teachers of low SES students in constructing workarounds to not only use technology to engage students in learning, but also to meet their professional obligations. However, only the teachers of high SES students employed technological practices that put them on target for the upcoming CCSS policy change. Prior to the implementation of CCSS, these teachers were using technology to provide students with opportunities to analyze and discuss current and historical primary sources in class and online. Since the teachers of high SES students exhibited the most freedom using technology to meet their professional goals, they will most likely continue to develop new ways to use technology to enrich students' learning, while teachers of low SES students remain complacent teaching to the test.

\section{Equity Costs of Current Technological Practices}

The findings in this study have uncovered contradictory practices regarding social science teachers' technology use across SES. While the teachers collectively agreed that they wanted to prepare students for college and career, students were not being provided with equitable skills and knowledge. For example, teachers of higher SES students used technology to engage their students in learning more critical thinking skills that they would need to succeed in college and career. However, teachers of low SES students distributed fragmented skills and knowledge that would most likely prepare them for lower-level positions. The dichotomy of these practices reveals the double-edged sword of how using technology can be both beneficial and detrimental to students' learning. 
Underlying this inequity were the thoughtless assurances made to low SES students by their social science teachers. On the one hand, by introducing low SES students to the promise of attending college, the teachers urged students to set aspirations above what many individuals in low-income communities have accomplished. On the other hand, by restricting and policing students' technology use in the classroom, it would be unlikely that students receive the critical thinking skills needed to succeed in college. While these teachers provided low SES students with high aspirations for their futures, they merely raised students' hopes and not their skills and knowledge. Thus, these teachers misled their students with the false hope (Duncan-Andrade, 2009) that if they did what they were told in class, they would have the same success in college as their higher SES peers.

In addition to exchanging obedience for false hope, teachers of low SES students promulgated their ideals of success and failure on a student body compromised of approximately $80 \%$ minority students. This is problematic when you have a predominantly Caucasian teaching force promoting their ethnocentric views on minority student groups (Picower, 2009). Latino, Asian, Pacific Islander, African-American and ELL students in this low SES school received the message that going to college and obtaining a professional job was the measure of success, while holding a blue-collar job was a sign of failure. Since many of these blue-collar jobs are held by minorities in lowincome communities, this emasculates the work students' parents, relatives or friends have done or are currently employed doing. Moreover, it disparages any career path 
students take that does not involve college or professional jobs. By continuing to support such disingenuous practices, these teachers unwittingly helped to perpetuate the idea that low SES students are not capable of the same success and achievement as their higher SES peers.

\section{Recommendations}

The following recommendations are based on the data gathered, analyzed and reported in this study. Though the findings have significant implications for social science teachers, school leaders, policymakers and researchers, they are limited by the size of the study. While qualitative studies provide depth and understanding to critical issues, they are narrow in scope. The small sample size of ten social science teachers in one specific area of California limits the extent to which the findings of the study can be generalized across all social science classrooms. Still, the findings lend themselves to other social science teachers, school leaders, policymakers and researchers in positions to learn and act upon these findings.

Recommendations for High School Social Science Teachers

1. At the middle and high SES schools, a total of four social science teachers provided students with online access to course materials. Although one of the teachers only provided access to course materials to her AP students, such access should be equitable for all students. Social science teachers at any SES level should provide students with digital copies of their lectures, presentations, visuals, primary sources, agendas and other course materials so that students can view 
these materials anytime they wish. However, equitable access to these materials is only part of the recommendation. Teachers cannot assume that students will use the information because it is online. Based on the findings of this study, teachers need to make these online spaces user-friendly in order for students to find value in using them.

2. The social science teachers in higher SES schools used technology to engage and enrich students' learning. It is recommended to other social science teachers to integrate similar uses of technology that capture students' interest. For example, teachers could take time to explore students' questions online, analyze and discuss primary sources, both written and visual, and incorporate students' smartphones and other devices for academic purposes. Teachers could build upon students' interests and use historically accurate sources online to create mini lessons that could provide more depth on these topics. Teachers could also utilize social networks to create online classroom communities where students could discuss and debate issues further or work together to construct alternative solutions to current or historical problems. Teachers could use these forums to facilitate student collaboration to complete assignments and projects.

3. Low and middle SES teachers unwittingly prepared students for specific socioeconomic positions in our society based upon the learning opportunities they received. However, the high SES teachers articulated that their goal was to prepare their students to become the leaders of tomorrow. Due to this finding, it 
is recommended that social science teachers reflect on their own pedagogies and determine how their lessons positively and negatively impact their students' futures. Teachers should share the goal of providing all students with a strong foundation in the social sciences and technology to help students develop skills needed to succeed in the $21^{\text {st }}$ century.

Recommendations for School Leaders

1. Based on the findings of this study, all of the high school teachers experienced similar problems accessing and using technology. However, only middle and high SES teachers were able to create solutions that allowed them to utilize technology for teaching and learning. Instead of the burden being placed on innovative teachers to create workarounds, school leaders need to ensure that all technology on campus is functioning and accessible on a daily basis.

2. School leaders should also provide new technological trainings for teachers to restructure their lessons to meet CCSS. Across SES, teachers in this study had to seek out digital trainings on websites like PBS because their schools did not provide these learning opportunities. While this study showed that testing influenced teachers' technological practices, teachers at the higher SES schools found innovative ways to use technology to engage students in an enriched curriculum. School leaders should offer teachers trainings on how to use teacher and student-centered technologies in ways that enhance classroom learning. 


\section{Recommendations for Policymakers}

1. This study found that the current method of measuring equitable computer access for students creates serious misunderstandings in evaluating the availability and use of technology. The current measure works as a simple mathematical ratio, students: computers, for the entire school site. More accurate measures of access should include access to functional technology in classrooms, computer labs, libraries and mobile computer carts. This census should also include the number of students who have access to electronic devices like smartphones. These measures can be further categorized by the nuances of operability, such as age, operating system, memory and speed. This is an example of what Badway and Erwin (2002) have noted as factors that cause confusion and miscommunication. In some cases, educational practitioners assume they are talking about the same aspect of learning when they in fact are not, and at other times use different terms without recognizing that they are referring to the same aspect of learning. This terminology confusion leads to the next recommendation.

2. Another category for measuring Internet usage should be added. A list should be complied by a school's Information Technology (IT) department to determine which websites are visited and the frequency with which they are accessed. These lists could be broken down to distinguish between Internet usage by administrators, teachers and students. Having this information would foster datadriven dialogues about how different groups of people on campus are using the 
Internet, identify best practices and share this information with the teachers and students at the school to foster equitable Internet usage.

3. This study illustrates that teachers of low SES students provided them with limited opportunities to use technology in favor of spending more time preparing for standardized tests. To encourage more equitable access and use of technology, policymakers should consider allowing students to submit technology-based projects as proof of their learning. These projects could be done at any time during the school year and would provide teachers with the flexibility to assign technology-based projects more often. By making this part of the assessment, teachers would not have to choose between providing students with access to technology or preparing them for a high-stakes test.

\section{Recommendations for Further Study}

1. One of the findings from this study revealed a problem with technology access ratios and another study could be formulated to measure the evolution of the digital divide. This study could utilize the measures recommended in the prior section to provide a more accurate picture of technological access and use in schools. That study would reveal a more precise look at where a school's technological hardware is located and how much of these technologies are functionally ready to use. Researchers could use this information to better assess digital inequities in schools and make recommendations to improve them. 
2. In this study, the social science teachers reported on what their past technological practices were under NCLB. However, this study was conducted on the cusp of CCSS. The findings demonstrate that all of the teachers were aware of the new educational policy and those in the middle and high SES schools were already preparing for the change. In the 2014/15 school year, CCSS will be implemented and this study could be replicated. Replicating this study would allow the researcher to compare the findings to determine the evolution of social science teachers' technological practices. The researcher could also report on the extent to which CCSS influences the teachers' technological practices.

\section{Conclusion}

Despite being next to the Silicon Valley, this study revealed that the digital divide is alive and well. Low-income students lacked access to technology because of antiquated and inoperable technology and social science teachers' goals were to impart facts rather than the preparation for informed participation in society. Higher-income students also lacked reliable technologies, but teachers at those schools developed workarounds to technological challenges to impart critical thinking skills.

Though all of the social science teachers used technology for direct instruction, teachers at the middle SES school enriched their curriculum with digital resources, interactive presentations and games and the exploration of students' interests online. In contrast to the low SES school, students at the higher-income schools were given more opportunities to use computers in the labs, from mobile carts or their smartphones. 
Furthermore, the teachers at the high SES school integrated more student-centered technological learning activities than the other schools. High SES teachers also created opportunities for students to present content material to their peers, instead of relying on teacher-centered lectures as done at the lower-income schools. This difference illustrated how higher SES students were active developers and presenters of knowledge while low SES students acted as passive receivers of information.

This study revealed that middle and high SES used technology more effectively to balance their professional obligations to prepare students for standardized tests, college and careers than low SES teachers. Middle and high SES students were also more engaged in learning through technology use than their low SES peers. These difference experiences with technology were found to perpetuate class differences and foster social reproduction.

Due to this inequity, the study demonstrates that the social science teachers reinforced socioeconomic hierarchies by providing students with dissimilar technological learning opportunities. As SES increased, so did students' opportunities to access and use technology for learning. Restricting students' technology usage in the low-income school translates into limited skill attainment that would not afford them many opportunities later in life. As technological opportunities increased in the middle and high-income schools, the more likely students were to be prepared for professional and leadership positions. 
It is the hope of this researcher that these findings can be used to further research into the evolution of the digital divide and social science teachers' technological practices. With the distribution of knowledge regarding this inequity, it may encourage current social science teachers to provide students with broader technological learning opportunities that stop perpetuating social hierarchies and social reproduction. 


\section{References}

Anderson, R. E. \& Becker, H. J. (2001). School investments in instructional technology. Report 8. Teaching, Learning and Computing: 1998 National Survey. Irvine, CA: Center for Research on Information Technology and Organizations.

Attewell, P. (2001). The first and second digital divides. Sociology of Education, 74(3), 252-59.

Badway, N. N. \& Erwin, D. (2002). The language of student outcomes: A vocabulary. Commissioned paper prepared for National Postsecondary Education Cooperative. Washington DC: National Center for Education Statistics.

Banister, S., \& Fischer, J. (2010). Overcoming the Digital Divide: The Story of an Urban Middle School. Mid-Western Educational Researcher, 23(2), 2-9.

Banister, S. \& Vannata Reinhart, R. (2011). TPCK for impact: Classroom teaching practices that promote social justice and narrow the digital divide in an urban middle school. Computers in the Schools, 28(1), 5-26.

Basham, J. D., Meyer, H. \& Perry, E. (2010). The design and application of the digital backpack. Journal of Research on Technology in Education, 42(2), 339-359.

Bebell, D., Russell, M. \& O'Dwyer, L. (2004). Measuring teachers' technology uses: Why multiple-measures are more revealing. Journal of Research on Technology in Education, 37(1), 45-63.

Becker, J. D. (2006). Digital equity in education: A multilevel examination of differences 
in and relationships between computer access, computer use and state-level technology policies. Educational Policy Analysis Archives, 15(3).

Bernard, S. C. \& Mondale, S. (2001). School: The story of American public education. Boston, MA: Beacon Press.

Bogdan, R. C. \& Biklen, S. K. (2007). Qualitative research for education: An introduction to theories and methods. Boston, MA: Allyn and Bacon.

Booth, J. (2008). The influence of professional development in technology integration on teacher pedagogy and student engagement in fourth and fifth grade elementary classrooms in an urban elementary school in the northeast. Johnson \& Wales University. ProQuest Dissertations and Theses, 132.

British Educational Communications and Technology Agency. (2006). The Becta Review 2006: Evidence on the progress of ICT in education. Coventry: British Educational Communications and Technology Agency.

Bryant, D. M. (2010). Technology resolved: An ethnographic approach to instructional design within urban middle school debate. Georgia State University. ProQuest Dissertations and Theses, 238.

Butin, D. W. (2010). The education dissertation: A guide for practitioner scholars. Thousand Oaks, CA: Corwin.

California Faculty Association. (2009). California at the edge of a cliff: The failure to invest in public higher education is crushing the economy and crippling our kids' future. Sacramento, CA. Mortenson, T. 
Creswell, J. W. (2002). Educational research: Planning, conducting, and evaluating quantitative and qualitative research. Upper Saddle River, NJ: Pearson Education.

Cuban, L., Kirkpatrick, H., \& Peck, C. (2001). High Access and Low Use of Technologies in High School Classrooms: Explaining an Apparent Paradox. American Educational Research Journal, 38(4), 813-34.

Culp, K., Honey, M. \& Mandinach, E. (2005). A retrospective on twenty years of education technology policy. Journal of Educational Computing Research, 32(3), 279-307.

DeWitt, S. W. (2007). Dividing the digital divide: Instructional use of computers in social studies. Theory and Research in Social Education, 35(2), 277-304.

Doppen, F. H. (2004). Beginning social studies teachers' integration of technology in the history classroom. Theory and Research in Social Education, 32(2), 248-279.

Dubin, A. E. (2006). Conversations with principals: Issues, values, and politics. Thousand Oaks, CA: Sage Publications.

Duncan-Andrade, J. M., Morrell, E. (2008). The art of critical pedagogy: Possibilities for moving from theory to practice in urban schools. New York, NY: Peter Lang.

Duncan-Andrade, J. (2009). Note to educators: Hope required when growing roses in concrete. Harvard Educational Review, 79(2), 181-194.

Eamon, M. (2006). A "genuine relationship with the actual": New perspectives on 
primary sources, history and the Internet in the classroom. History Teacher, 39(3), 297-314.

Ertmer, P. A., Ottenbreit-Leftwich, A. T., Sadik, O., Sendurur, E. \& Sendurur, P. (2012). Teacher beliefs and technology integration practices: A critical relationship. Computers and Education, 59(2), 423-435.

Fassett, D. L., \& Warren, J. T. (2004). "You get pushed back": The strategic rhetoric of educational success and failure in higher education. Communication Education, $53,21-39$.

Finn, P. (1999). Literacy with an Attitude: Educating Working-Class Children in Their Own Self-Interest. State University of New York Press. 9-25.

Frazier, M. T. (2009). The effect of technology education on students' state standardized test scores. Old Dominion University. ProQuest Dissertations and Theses, 87.

Gorski, P. (2005). Education equity and the digital divide. Association for the Advancement of Computers in Education Journal, 13(1), 3-45.

Hannafin, R. D. (2008). K-12 technology audit: Lessons for school leaders. International Electronic Journal for Leadership in Learning, 12(6). 1-27.

Harris, J. B. \& Hofer, M. J. (2011). Technological pedagogical content knowledge (TPACK) in action: A descriptive study of secondary teachers' curriculumbased, technology-related instructional planning. Journal of Research on Technology in Education, 43(3), 211-229. 
Heafner, T. L. \& Friedman, A. M. (2008). Wikis and constructivism in secondary social studies: Fostering a deeper understanding. Computers in the Schools, 25(3-4), 288-302.

Hicks, D., Doolittle, P. \& Lee, J. K. (2004). Social studies teachers' use of classroombased and web-based historical primary sources. Theory and Research in Social Education, 32(2), 213-247.

Hofer, M. \& Swan, K. O. (2009). Technological pedagogical content knowledge in action: A case study of a middle school digital documentary project. Journal of Research on Technology in Education, 41(2), 179-200.

Hohlfeld, T. N., Ritzhaupt, A. D., Barron, A. E. \& Kemker, K. (2008). Examining the digital divide in k-12 public schools: Four-year trends for supporting ICT literacy in Florida. Computers \& Education, 51(4), 1648-1663.

Johannesen, R. L., Walde, K. S. \& Whedbee, K. E. (2008). Ethics in human communication. Long Grove, IL: Waveland Press, Inc.

Johnson, S. L. (2011). Effectively using presentation technology in the history classroom. Walden University. ProQuest Dissertations and Theses, 158.

Kennedy, M. (2010). Technology in schools: A practical look at interactive whiteboards in secondary social studies classrooms. Pacific Lutheran University. ProQuest Dissertations and Theses, 80.

Kim, M. C. \& Kim, J. K. (2001). Digital divide: Conceptual discussions and prospect. Human Society and the Internet, Proceedings (LNCS), 2105, 78-91. 
Kleiman, G. M. (2000). Myths and realities about technology in k-12 schools. In the Harvard Education Letter report, The digital classroom: How technology is changing the way we teach and learn.

Kleiman, G. M. (2004). Myths and realities about technology in k-12 schools: Five years later. Contemporary Issues in Technology and Teacher Education [Online serial], 4(2).

Levy, F. \& Murnane, R. J. (2004). Education and the changing job market. Educational Leadership, 62(2), 80.

Lively, B. R. (2010). A study of the impact of the classroom performance system (CPS) on fourth and fifth grade student social studies academic performance. Walden University. ProQuest Dissertations and Theses, 91.

Lowther, D. L., Ross, S. M. \& Morrison, G. M. (2003). When each one has one: The influences on teaching strategies and student achievement of using laptops in the classroom. Educational Technology Research and Development, 51(3), 23-44.

Marshall, C. \& Rossman, G. B. (2011). Designing qualitative research. Thousand Oaks, CA: Sage Publications.

McGlinn, M. (2007). Using the "Documenting the American South" Digital Library in the social studies: A case study of the experiences of teachers in the field. Contemporary Issues in Technology and Teacher Education, 7(1), 529-553.

Muir-Herzig, R. G. (2004). Technology and its impact in the classroom. Computers and Education, 42(2), 111-131. 
Parsad, B. \& Jones, J. (2005). Internet access in US public schools and classrooms: 1994-2003 (NCES 2005-015). Washington DC: US Department of Education, National Center for Educational Statistics.

Patton, M. Q. (2002). Qualitative research and evaluation methods. Thousand Oaks, CA: Sage.

Peck, C., Mullen, C. A., Lashley, C. \& Eldridge, J. A. (2011). School leadership and technology challenges: Lessons from a new American high school. AASA Journal of Scholarship \& Practice, 7(4), 39-51.

Picower, B. (2009). The unexamined Whiteness of teaching: How White teachers maintain and enact dominant racial ideologies. Race, Ethnicity and Education, 12(2), 197-215.

Prensky, M. (2008). Turning on the lights. Educational Leadership, 65(6),40-45.

Rakes, G. C., Fields, V. S. \& Cox, K. E. (2006). The influence of teachers' technology use on instructional practices. Journal of Research on Technology in Education, 38(4), 409-424.

Ravitch, D. (2010). The death and life of the great American school system: How testing and choice are undermining education. New York, NY: Basic Books.

Roth, W. M. \& Tobin, K. (2010). Solidarity and conflict: Aligned and misaligned prosody as a transactional resource in intra- and intercultural communication involving power differences. Cultural Studies of Science Education, 5, 807-847.

Rowand, C. (2000). Teacher use of computers and the Internet in public schools. 
Education Statistics Quarterly, 2(2), 72-75.

Stake, R. E. (2010). Qualitative research: Studying how things work. New York, NY: Guilford Press.

Schleicher, J. L. (2011). Impact of netbook computers on one district's social studies curriculum. University of North Dakota. ProQuest Dissertations and Theses, 204.

Seiler, G., Tobin, K. \& Sokolic, J. (2001). Design, technology and science: Sites for learning, resistance and social reproduction in urban schools. Journal of Research in Science Teaching, 38(7), 746-67.

Wagner, T. (2008). The global achievement gap: Why even our best schools don't teach the new survival skills our children need-and what we can do about it. New York, NY: Basic Books.

Warschauer, M., Knobel, M. \& Stone, L. (2004). Technology and equity in schooling: Deconstructing the digital divide. Educational Policy, 18(4), 562-588.

Warschauer, M. (2007). The paradoxical future of digital learning. Learning Inquiry, 1 (1), 41-49.

Warschauer, M. \& Matuchniak, T. (2010). New technology and digital worlds: Analyzing evidence of equity in access, use and outcomes. Review of Research in Education, 34(1), 179-225.

Watson, D. (2006). Understanding the relationship between ICT and education means exploring innovation and change. Education Information Technology, 11, 199216. 
Wenglinsky, H. (2006). Technology and achievement: The bottom line. Educational Leadership, 63(4), 29-32.

Wood, L. \& Howley, A. (2012). Dividing at an early age: The hidden digital divide in Ohio elementary schools. Learning, Media and Technology, 37(1), 20-39.

Zhao, Y. (2007). Social studies teachers' perspectives of technology integration. Technology and Teacher Education, 15(3), 311-333.

Zucker, A. A. \& Hug, S. T. (2008). Teaching and learning physics in a 1:1 laptop school. Journal of Science Education and Technology, 17(6), 586-594. 
Appendix

Instrumentation

1. Can you describe your role and responsibilities at the school?

2. What kinds of technologies are available for teachers and students for students to use?

3. Would you explain how and why you are using these technologies for teaching and learning?

4. How often are you using technology in these ways?

5. Have you received any help using these technologies in your classroom?

6. What challenges have you encountered when using technology in these ways?

7. What are your goals for using technology in the classroom?

8. How has technology helped you in achieving these goals?

9. How have these technologies influenced your teaching?

10. Is there anything else that you would like to add that I have not asked you about? 